\title{
$2+2 x$
}

Linköping Studies in Science and Technology Dissertation No. 2010

$H^{2}+2=$

$$
-8 \cdot x^{2}
$$

\section{Monitoring of product}

variants in biopharmaceutical tr $_{2}$ downstream processing:

Mechanistic and data-driven modeling approaches

\section{Patricia Roch}
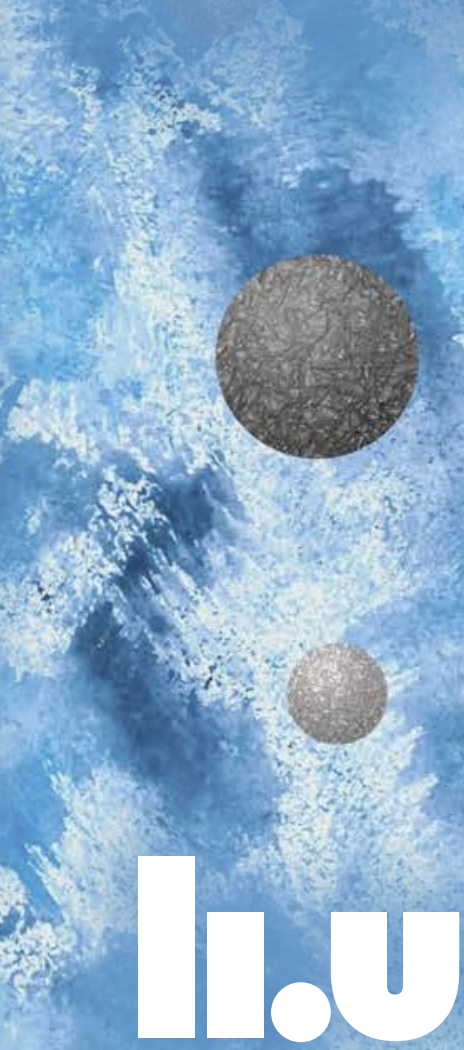

\section{LINKÖPING UNIVERSITY}


Linköping Studies in Science and Technology

Dissertation No. 2010

\title{
Monitoring of product variants in biopharmaceutical downstream processing: Mechanistic and data-driven modeling approaches
}

\author{
Patricia Roch
}

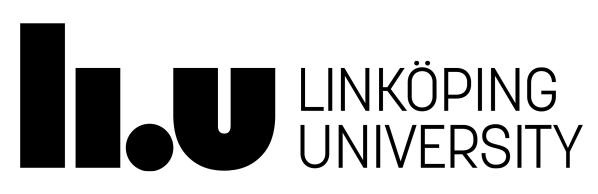

Division of Biotechnology

Department of Physics, Chemistry and Biology

Linköping University, Sweden

Linköping 2019 
Cover: Artistic illustration of chromatographic column's inside with an antibody and B chain of insulin (not to scale).

During the course of the research underlying this thesis, Patricia Roch was enrolled in Forum Scientium, a multidisciplinary doctoral programme at Linköping University, Sweden.

(c) Copyright 2019 Patricia Roch, unless otherwise noted

Roch, Patricia

Monitoring of product variants in biopharmaceutical downstream processing: Mechanistic and data-driven modeling approaches ISBN: 978-91-7685-002-2

ISSN: 0345-7524

Printed in Sweden by LiU-Tryck, Linköping 2019 


\section{Abstract}

During the manufacturing of biopharmaceuticals, a multistep purification strategy is employed to remove process-related impurities and product variants, to achieve high product quality, assuring patients' safety. To guarantee that biopharmaceuticals are safe and to accomplish quality, strict policies were established by regulatory agencies as well as guiding principles, such as Quality by Design and process analytical technology. To make the manufacturing process economical, relatively high product yield and productivity are also desirable.

The removal of product variants often poses a challenge in downstream processing due to their structural similarity to the product resulting in similar behavior. One way of overcoming this issue is to employ additional monitoring tools capable to distinguish between the product and product variants.

This thesis demonstrates the development of novel monitoring tools, based on existing monitoring and modeling approaches, to facilitate downstream processing.

Existing techniques are evaluated and critically compared toward meeting the requirements on monitoring quality attributes in downstream processing.

A mechanistic model-based monitoring tool was established for a reversed phase chromatography polishing step of insulin to predict the elution profile of insulin and two insulin variants. By relying on model-based monitoring a significant increase in product yield was achieved.

Further, multi-wavelength fluorescence spectroscopy coupled with the multi-way algorithm parallel factor analysis was utilized to monitor product variants of biopharmaceuticals in downstream processing. This monitoring tool capitalizes on a shift in fluorescence emission between the product and its variant. Developed for monitoring aggregates during antibody purification, the transferability of the approach to other 
relevant biopharmaceuticals, such as factor VIII and erythropoietin, has been confirmed.

The monitoring tools developed in this thesis, extend existing monitoring tools for downstream processing of biopharmaceuticals. When implementing these monitoring tools into the different phases of biopharmaceuticals' lifespan, their potential could range from optimizing downstream processes during purification strategy development to supporting manufacturing by facilitating process decisions. 


\section{Populärvetenskaplig sammanfattning}

I tillverkningsprocesser för framställning av läkemedelsproteiner ingår flera reningssteg som tar bort föroreningar för att uppnå en säker produkt för patienterna. Föroreningarna utgörs antingen av varianter av läkemedelsproteinet eller av andra föroreningar från tillsatser som görs eller uppkommer i tillverkningsprocessen. Strikta regelverk, standarder och riktlinjer, som Quality by Design och Process Analytical Technology, som utfärdas av läkemedelsverk och andra organisationer säkerställer att tillverkningen av läkemedelsproteiner uppnår tillräckligt hög kvalitet för att kunna godkännas för behandling av patienter. För att dessutom uppnå en kostnadseffektiv tillverkningsprocess behöver man också uppnå högt produktutbyte och hög produktivitet.

Effektiv borttagning av produktvarianter förutsätter väl fungerade reningssteg i tillverkningsprocessen eftersom produkten och produktvarianten är strukturellt lika varandra. För att vara framgångsrik med det har man stor nytta av analytiska verktyg som snabbt och tillförlitligt kan särskilja och kvantifiera produkt och produktvarianter och på så vis övervaka effektiviteten i reningsprocessens förlopp.

Den här avhandlingen handlar om utveckling av sådana analysverktyg för övervakning. Som utgångspunkt i avhandlingsarbetet har existerande analys- och modelleringsmetoder för proteiner ingående utvärderats och kritiskt jämförts mot de krav som ställs på monitorering av viktiga kvalitetsegenskaper vid proteinrening.

I ett av avhandlingens arbeten har en mekanistisk modell för kromatografi använts för monitorering av ett reningssteg $i$ en insulintillverkningsprocess. Den mekanistiska modellen kunde förutsäga förekomsten av insulin och två insulinvarianter och underlättade att ta processbeslut som gav en betydande ökning av produktutbytet. 
I avhandlingen har även ett annat analysverktyg utvecklats för monitorering av produktvarianter som bygger på fluorescensspektroskopi i kombination med den kemometriska metoden parallel factor analysis. Analysverktyget utnyttjar förändringar i fluorescensemission mellan produkt och produktvariant. Metodiken utvecklades först för övervakning av proteinaggregat vid en reningsprocess för $\mathrm{i}$ antikroppstillverkning. Därefter användes analysverktygen framgångsrikt för analys av varianter från läkemedelsproteinerna faktor VIII och erytropoetin.

Analysverktygen som utvecklats i avhandlingen tillför nya möjligheter för övervakning av biotekniska reningsprocesser för läkemedelsproteiner. Om verktygen tillämpas industriellt för processutveckling och produktion av läkemedelsproteiner, finns goda förutsättningar att förbättra optimering av reningsprocesser och att underlätta viktiga processbeslut i tillverkningsprocessen. 


\section{List of Publications}

This thesis is based on the following publications:

\section{Paper I}

P. Roch, C.-F. Mandenius

On-line monitoring of downstream bioprocesses

Current Opinion in Chemical Engineering 2016, 14:112-120

Contribution: Performed all research and evaluation. Wrote manuscript with co-author.

\section{Paper II}

P. Roch, A. Sellberg, N. Andersson, M. Gunne, P. Hauptmann, B. Nilsson, C.-F. Mandenius

Model-based monitoring of industrial reversed phase chromatography to predict insulin variants

Biotechnology Progress 2019, 35(4):e2813

Contribution: Conceived study, planned and conducted all experiments, calibrated the model together with A.S., N.A., B.N. and wrote main part of article.

\section{Paper III}

P. Roch, I. G. Ivanov, C.-F. Mandenius

Improving Process Monitoring of Protein Purification by Combining Fluorescence Spectroscopy and Multi-way Analysis Submitted 2019 
Contribution: Planned and performed all experimental work. Analyzed and modeled the data. Wrote the majority of the manuscript.

\section{Paper IV}

P. Roch, I. G. Ivanov, C.-F. Mandenius

Transferability of Fluorescence Spectroscopy Coupled with Multi-way Analysis for Monitoring of Biopharmaceutical Product Variants

Manuscript 2019

Contribution: Planned and conducted all experiments. Analyzed and modeled the data. Wrote the main part of the manuscript.

This thesis contains unpublished data in addition to the included papers. 


$\begin{array}{ll}\text { Abbreviations } & \\ \text { AEX } & \text { Anion exchange } \\ \text { CEX } & \text { Cation exchange } \\ \text { CHO } & \text { Chinese hamster ovary } \\ \text { CIP } & \text { Cleaning-in-place } \\ \text { CPP } & \text { Critical process parameter } \\ \text { CQA } & \text { Critical quality attribute } \\ \text { DNA } & \text { Deoxyribonucleic acid } \\ \text { DOE } & \text { Design of experiment } \\ \text { DSP } & \text { Downstream processing } \\ \text { EPO } & \text { Erythropoietin } \\ \text { FDA } & \text { Food and Drug Administration } \\ \text { FTIR } & \text { Fourier transform infrared } \\ \text { HCP } & \text { Host cell protein } \\ \text { HPLC } & \text { High performance liquid chromatography } \\ \text { IgA } & \text { Immunoglobulin A } \\ \text { IgG } & \text { Immunoglobulin G } \\ \text { mAb } & \text { monoclonal antibody } \\ \text { MVDA } & \text { Multivariate data analysis } \\ \text { MW } & \text { Molecular weight } \\ \text { ODE } & \text { Ordinary differential equation } \\ \text { PARAFAC } & \text { Parallel factor analysis } \\ \text { PAT } & \text { Process analytical technology } \\ \text { PCA } & \text { Principal component analysis } \\ \text { PCR } & \text { Principal component regression } \\ \text { PLS } & \text { Partial least squares } \\ \text { QbD } & \text { Quality by Design } \\ \text { RMSEC } & \text { Root mean square error of calibration } \\ \text { RMSEP } & \text { Root mean square error of prediction } \\ \text { RPC } & \text { Reversed phase chromatography } \\ \text { USP } & \text { Upstream processing } \\ \text { UV } & \text { Ultraviolet } \\ \text { VIS } & \text { Visible } \\ & \end{array}$




\section{Contents}

Abstract I

Populärvetenskaplig sammanfattning III

Publications V

$\begin{array}{lll}\text { Abbreviations } & \text { VII }\end{array}$

1 Introduction 1

1.1 Biopharmaceutical downstream processing . . . . . . . . 1

1.2 Monitoring tools . . . . . . . . . . . . . . . . 1

1.3 Aim and scope . . . . . . . . . . . . . . . 2

2 The need for monitoring in the biopharmaceutical industry 5

2.1 Biopharmaceutical industry in general . . . . . . . 5

2.2 Production of recombinant proteins . . . . . . . . . 6

2.3 Purification of recombinant proteins . . . . . . . . . 6

2.3.1 Chromatography . . . . . . . . . . 7

2.3.2 Process decisions in chromatography . . . . . . 8

2.3.3 Process- and product-related impurities . . . . . . 8

2.3.4 Process variability . . . . . . . . . . . . . . . . 9

2.4 Quality by Design . . . . . . . . . . . . . . . . 9

2.4.1 Critical quality attributes . . . . . . . . . . . 10

2.4.2 Process analytical technology . . . . . . . . . . 11

2.5 Examples of recombinant proteins . . . . . . . . . . 12

3 Current practices and future possibilities in downstream $\begin{array}{ll}\text { process monitoring } & 15\end{array}$

3.1 Attributes of interest . . . . . . . . . . . . . . 15

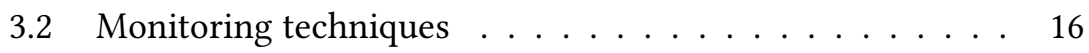


3.2 .1 Spectroscopy . . . . . . . . . . . . . . . 17

3.3 The soft sensor concept for downstream process monitoring 19

3.4 Impact of monitoring on quality and process economy . . 20

4 Modeling approaches to enhance downstream processing 23

4.1 Mechanistic models . . . . . . . . . . . . . . . 23

4.1.1 Chromatography models . . . . . . . . . . . . . 23

4.1.2 Modeling reversed phase chromatography . . . . . 24

4.1 .3 Model sensitivity . . . . . . . . . . . . . . 26

4.2 Data-driven models . . . . . . . . . . . . . . . . . 27

4.2.1 Multivariate data analysis . . . . . . . . . 28

4.2.2 Principal component analysis, principal component regression and partial least squares regression . . . . . . . . . . . . . 28

4.2.3 Parallel factor analysis . . . . . . . . . . . . . 31

4.3 Model validation and limitations . . . . . . . . . . . . . 32

4.4 A comparison of mechanistic and data-driven models . . . 33

5 Novel tools based on existing monitoring and modeling approaches to monitor downstream processing 35

5.1 Mechanistic model-based monitoring . . . . . . . . . 35

5.2 PARAFAC-based multi-wavelength fluorescence monitoring 42

5.3 A comparison of the developed monitoring tools . . . . . 48

6 Conclusion and outlook $\quad 51$

Acknowledgment $\quad 55$

$\begin{array}{ll}\text { References } & 57\end{array}$ 


\section{Chapter 1}

\section{Introduction}

\subsection{Biopharmaceutical downstream processing}

Today's biopharmaceutical industry faces increased competition due to generic products and greater regulatory demands [1]. The development of new biopharmaceuticals to treat diseases and improve quality of life is time-consuming and expensive. Modeling has been used early on to evaluate process economics or optimize bioprocesses $[2,3]$ and modeling approaches should be further exploited to support the development phase and manufacturing of biopharmaceuticals.

The manufacturing of biopharmaceuticals consists of upstream and downstream processing. First, the desired product is produced in genetically engineered host cells and then the product is purified by separating undesired impurities. Impurities comprise, for example, cellular debris, other proteins or product variants which are structurally similar to the product but might cause adverse effects [4].

The aim of downstream processing (DSP) is to obtain a product of pre-defined quality and purity that fulfills regulatory requirements, guaranteeing patient's safety.

Biopharmaceutical production can be focused on achieving end-product quality or on ensuring product quality at all stages of the production. The latter has been emphasized in the last 20 years and focuses on product and process understanding.

\subsection{Monitoring tools}

Monitoring tools aim to provide additional information about the process of interest and to support decision making and control. 
Monitoring tools incorporate hardware sensors whose signals are processed by a model, or monitoring tools can solely rely on mathematical models. Models are a simplification of the real system aiming to understand the system, gain insight and predict its behavior. Mechanistic models mathematically describe underlying mechanisms and phenomena of the system. Those models represent knowledge of the system and its model parameters have physical, chemical or biological meaning.

Data-driven models process measured data by fitting a generic model to describe the input-output relationship of a system. Additional information on an attribute that cannot easily be measured directly thereby can be accessed.

Monitoring tools are evaluated toward their ability to monitor the attribute of interest, their accuracy and time to provide the desired information.

\subsection{Aim and scope}

The aim of this thesis is the advancement of process monitoring in biopharmaceutical downstream processing. The focus lies on monitoring of chromatography and the objective of each paper contributing to this thesis, is indicated in Figure 1.1.

An important part of this thesis was to identify attributes of interest to monitor in biopharmaceutical downstream processing and to find as well as critically compare analytical techniques capable to measure those attributes (Paper I).

This thesis seeks to develop new monitoring tools based on existing monitoring techniques and modeling approaches. Mechanistic model-based monitoring was developed for a chromatography polishing step of insulin. The approach was evaluated with industrial material and the pooling decision based on the mechanistic model was compared to current practices (Paper II).

Secondly, a monitoring tool was developed, comprising of multi-wavelength fluorescence spectroscopy and the data-driven model parallel factor analysis (PARAFAC). This monitoring tool was developed for an immunoglobulin G (IgG) purification process (Paper III). Paper IV expands this research by investigating the transferability of this methodology to monitor other biopharmaceuticals. 
The thesis commences by providing a background to the biopharmaceutical industry, describing the need for monitoring in the biopharmaceutical industry and further how monitoring aligns with the Quality by Design $(\mathrm{QbD})$ principle. Important attributes to monitor are discussed and the goal of how to ultimately implement monitoring tools into downstream processing is outlined. Fundamentals of the different modeling approaches and their evaluation and validation are provided. Further, the concepts of the developed novel monitoring tools are presented and compared. Then the main findings are summarized, put in perspective and future work is considered.

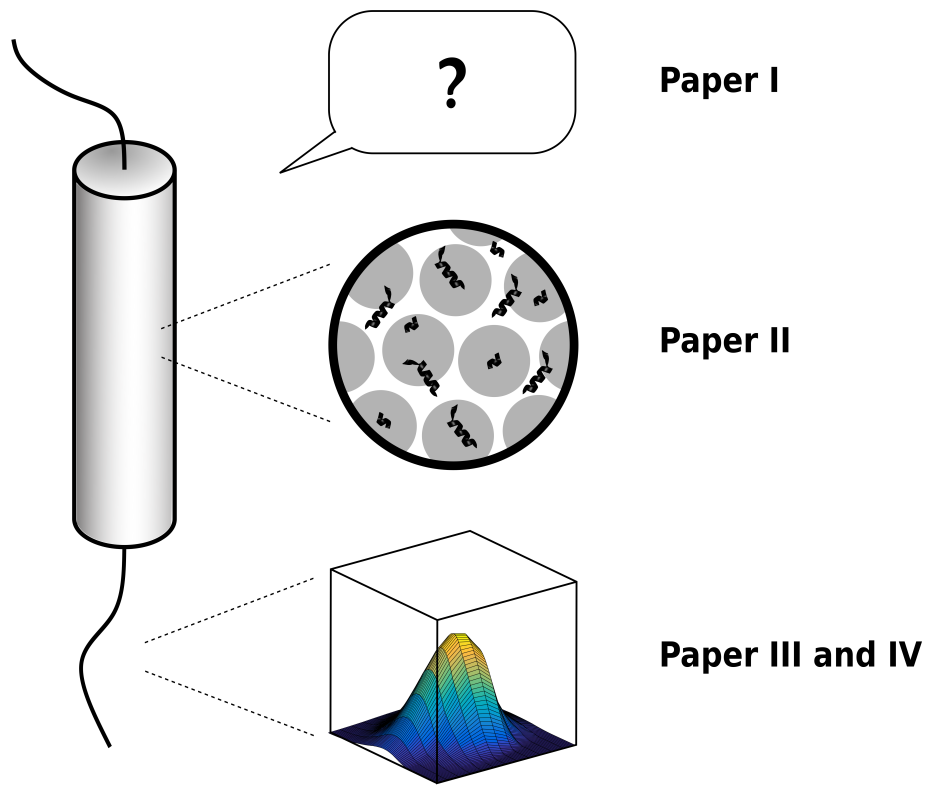

Figure 1.1: Overview of the papers comprised in this thesis. Paper I answers why monitoring of downstream processing should be considered, what to monitor and how it can be achieved. Paper II describes a mechanistic modeling approach to monitor chromatography. Paper III and IV utilize fluorescence spectroscopy and a data-driven modeling approach for monitoring. 
CHAPTER 1. INTRODUCTION 


\section{Chapter 2}

\section{The need for monitoring in the biopharmaceutical industry}

\subsection{Biopharmaceutical industry in general}

The biopharmaceutical industry derives drug substances from living organisms whereas the traditional pharmaceutical industry produces drug substances by chemical synthesis.

Among the most successful biopharmaceuticals is the monoclonal antibody Adalimumab [5], distributed under the brand name Humira, to treat arthritis and Crohn's disease.

Of utmost priority in the biopharmaceutical industry is to guarantee patient safety by ensuring high product quality. This is enhanced by demands and control actions from pharmaceutical regulatory agencies.

The biopharmaceutical industry also desires efficient and cost-effective manufacturing due to increasing competition. Downstream processing, including chromatography, is considered to be the major bottleneck in manufacturing and is requiring substantial technological improvements [6]. Biopharmaceutical trends to tackle downstream bottlenecks include the use of continuous processes, more efficient bioprocessing in terms of yield as well as increased automation, monitoring and control [7, 8].

The $\mathrm{QbD}$ principle supports the development of monitoring and control strategies for the biopharmaceutical industry and is encouraged by the U.S. Food and Drug Administration (FDA) and other regulatory agencies. 
$\mathrm{QbD}$ emphasizes product and process understanding to ensure product quality throughout biopharmaceutical development and manufacturing to mitigate potential risks [9].

\subsection{Production of recombinant proteins}

Recombinant proteins are expressed by genetically engineered host organisms. Appropriate vectors to express the protein of interest are developed and transfected into the host cell organism. The cells are then cultured in carefully controlled conditions to produce the protein product during upstream processing (USP) $[10,11]$.

Depending on the protein of interest, requirements for functional activity and the desired yield, different host cell organisms are chosen. Bacteria, yeast, and mammalian cells are commonly used to produce recombinant proteins. Each system has its own advantages and challenges [12].

The choice of production system also influences the subsequent downstream processing. Each production system entails different challenges in the purification of the protein product [13].

\subsection{Purification of recombinant proteins}

Downstream processing consists of recovery and purification unit operations that isolate and separate the protein product. The aim is to deliver a protein product of pre-defined quality and purity.

During recovery, the product is isolated from the production system. Centrifugation and filtration are typical recovery unit operations. If the protein product is produced intracellularly, cell disruption is required as well as potentially protein refolding [13, 14].

Purification aims to separate the protein product from impurities and to reduce all impurities to acceptable levels. Membrane-based techniques, such as tangential flow filtration, and chromatography can be employed with the latter being the most common unit operation [15].

The type and sequence of unit operations depend on the protein product and the production system. Each unit operation is optimized to handle the product intermediate from the previous step. The product purity is increased with each unit operation, but also product losses occur. Therefore, optimizing the product yield of each unit operation is of interest. While the product yield can be compromised throughout the downstream process, product purity cannot. Process- and productrelated impurities need to be removed to ensure patient safety [15]. 


\subsubsection{Chromatography}

Chromatography is extensively used to separate the protein product from bulk impurities such as DNA or host cell proteins (HCPs). It is also applied for more challenging separations, such as product variants which have similar properties as the protein product but might cause adverse effects for patients [16]. Protein variants are, for example, fragments, aggregates, charge variants, or the protein product with different post-translational modifications.

Chromatography can achieve separation while preserving the structure and activity of the protein. Often multiple steps of chromatography are executed throughout a downstream process. Initially, a capturing step is performed to isolate, stabilize and concentrate the protein product. In an intermediate purification step, bulk impurities are removed and in subsequent polishing steps, trace impurities are separated requiring sufficient selectivity of the chromatographic technique [15].

Chromatographic techniques exploit differences in protein size, physicochemical properties, such as charge, hydrophobicity, and affinity to achieve protein separation [15]. The underlying physical principles are mass transfer through the chromatographic column where the proteins are transported within the mobile phase through the stationary phase. The proteins disperse axially and diffuse into the pores of the stationary phase (Figure 2.1). Subsequently, interactions between the proteins and the stationary phase occur resulting in protein separation.

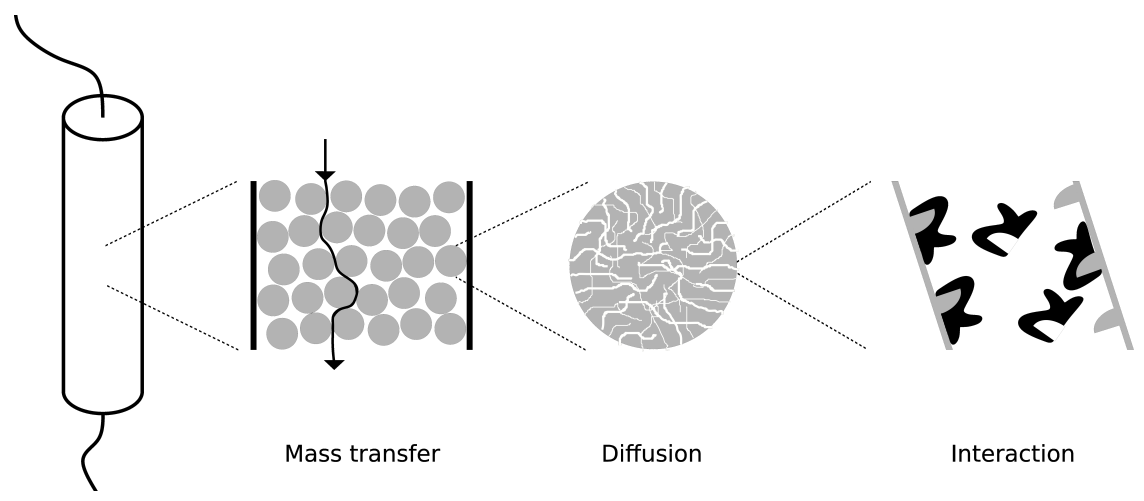

Figure 2.1: The principle of chromatography. The proteins, contained in the mobile phase, are transported through the column, diffuse into the pores of the stationary phase and interact with the stationary phase. 


\subsubsection{Process decisions in chromatography}

A critical operational procedure in chromatography is to collect the eluted product for the subsequent process step. This so-called pooling aims to achieve high product purity while also recovering as much product as possible.

Commonly, the decision on how to pool is based on the on-line monitoring of UV absorbance at $280 \mathrm{~nm}$, at the chromatography column outlet [14]. The advantage of UV-based pooling is its simplicity and when the entire eluted peak is collected, it works well (Figure 2.2a). When different proteins elute from the chromatography column, there is often an overlapping elution area (Figure 2.2b). This results in collecting just a part of the elution peak, which contains the product, to exclude impurities. The disadvantage of UV-based pooling is that product and impurities with similar absorbance profiles cannot be differentiated.

Usually, UV-based pooling decisions in manufacturing processes are established with a safety margin to account for possible process variability. Thereby product purity is ensured but consequently, the product yield is compromised.
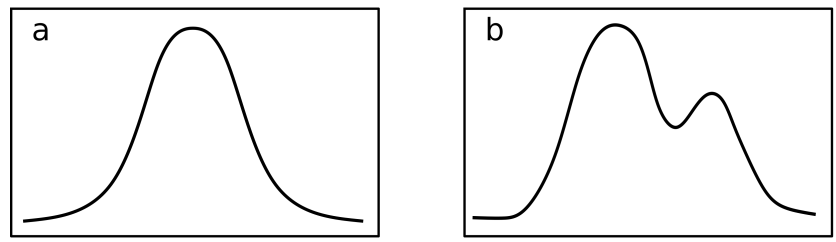

Figure 2.2: UV absorbance signal used to monitor the chromatography column outlet. a) Product elutes in one peak, b) Product coelutes with impurity.

\subsubsection{Process- and product-related impurities}

Impurities occurring during the purification of biopharmaceuticals can be differentiated into process- and product-related impurities. Process-related impurities are derived from e.g. the host cell organism, processing agents or materials. Examples are HCPs, DNA, endotoxins for gram-negative bacterial production systems or viruses for mammalian production systems. Impurities related to processing agents or materials are for example chemical additives such as surfactants or USP media components. Other example are leachables or extractables from used materials [13]. 
Product-related impurities are variants of the product whose properties differ from those of the product. Multimers, aggregates, fragments are common product-related impurities. Further, deamidated, oxidized, misfolded forms or incomplete posttranslational modifications are examples of variants of the product. Product variants can occur in upstream processing due to the heterogeneity of the biological systems, but variants can also arise throughout the entire manufacturing process or due to storage conditions $[17,18]$.

Product- and process-related impurities represent potential safety risks to the patient and therefore need to be removed or reduced below a certain limit. Product-related impurities are typically more challenging to separate from the product than process-related impurities due to their similar physicochemical properties resulting in similar behavior.

\subsubsection{Process variability}

There are many sources of variation in the production and purification process of biopharmaceuticals that can lead to variability throughout the process and potentially impact product quality. Already minor variability can affect the properties of the product [19]. Variability can occur in raw materials, through changes in the process, process equipment, operating conditions, and human factors. When process variability negatively impacts product quality, the product of a production batch cannot be released to the market. Therefore, the goal is to design robust processes that are capable to tolerate expected variability without compromising product quality.

\subsection{Quality by Design}

Quality by Design is a systematic approach that emphasizes product and process understanding as well as process control to ensure product safety and efficacy [9].

Historically, pharmaceutical production focused on end-product quality which was achieved by complying with established and regulatory-approved process boundaries. Since those approvals by regulatory agencies did not allow any changes to the process and product, there was a reluctance to use new technology which could improve the processes because new approval would have been required. The QbD principle was introduced to the pharmaceutical industry by the International Conference on Harmonisation and major regulatory 
agencies through a series of policies and guidelines in the 2000s [20-24]. This indicated a change in the biopharmaceutical industry from focusing on end-product quality toward building quality into the process. The science and risk-based approach fundamentally links patient requirements to the pharmaceutical product. $\mathrm{QbD}$ aims to ensure product quality at all stages of a product's lifespan from product development, third party suppliers to the manufacturing by understanding processes and mechanisms that contribute to product quality [25].

The QbD principle is illustrated in Figure 2.3. The quality target profile defines the characteristics of the product such as efficacy, patient safety, dosage, route of administration. Critical quality attributes (CQAs) and critical process parameters (CPPs) define the desired product and process performance. Risk assessment allows identifying potential sources of variability which could affect CQAs and CPPs. The interactions of CPPs on CQAs can be characterized by design of experiments (DOEs) allowing the setup of a design space to provide quality assurance. Working within the established design space will deliver the desired product quality, variability can be handled within the design space and process changes can be addressed faster. By developing control strategies for the manufacturing process, consistent quality can be assured over time. Continuous improvements are enabled through reporting and data management [9].

Each of these QbD elements is based on scientific knowledge, pharmaceutical quality system and quality risk and knowledge management. QbD is supported by modeling approaches such as DOEs or multivariate data analysis (MVDA). Process analytical technology (PAT) enables QbD. PAT comprises the identification of the attribute of interest, process monitoring techniques, such as sensors to measure the attribute, process modeling of the data generated by process monitoring technique and the control of the process [9].

In the following, elements of $\mathrm{QbD}$ particularly relevant for this thesis are discussed.

\subsubsection{Critical quality attributes}

CQAs are physical, chemical, biological or microbiological properties that describe the product quality according to the patient's needs [21]. Such needs are requirements regarding product purity, potency, immunogenicity, stability, etc. which are not just defined for the final product but also for intermediate products. 
CQAs can be impacted by variability in process conditions and raw material properties. Those conditions and properties need to be identified and their functional relationship with CQAs need to be investigated. If a CQA is not within its acceptable range or limit, the product cannot be released to the market because patient safety cannot be ensured. This underlines the need to establish monitoring and control strategies for the production process to be able to account for process variability which may affect critical quality attributes.

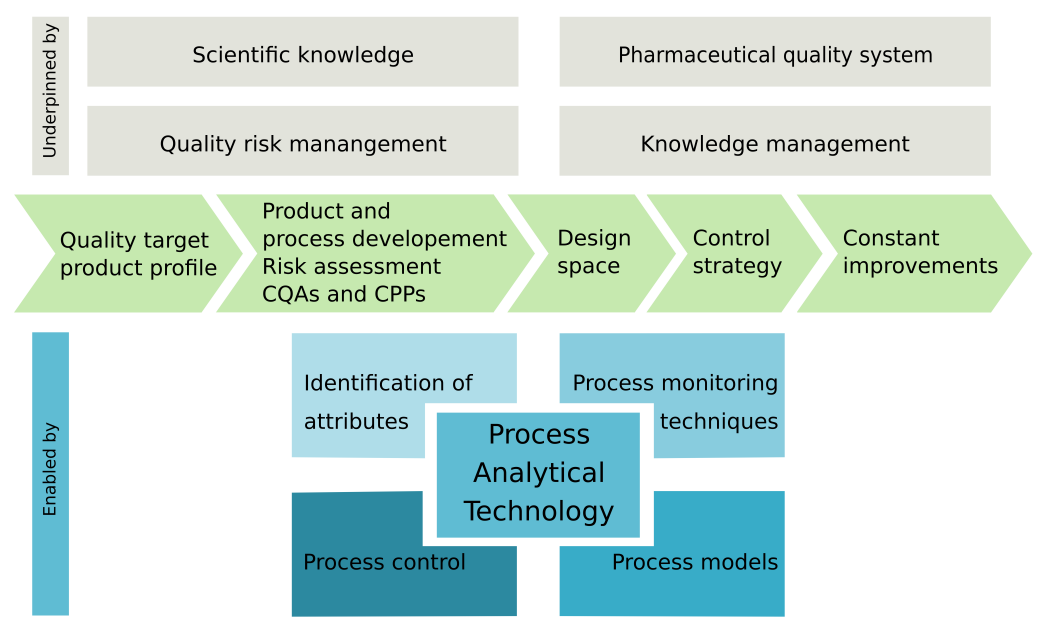

Figure 2.3: Illustration of the Quality by Design principle and the process analytical technology elements (redrawn from [9]).

\subsubsection{Process analytical technology}

QbD and PAT share similar goals of gaining process understanding to establish well-controlled manufacturing processes that ensure consistent product quality. PAT is required to accomplish the QbD principle and serves as a tool to ensure robust process performance by designing, analyzing, and controlling manufacturing processes. This requires PAT tools that provide timely measurements of critical quality and performance attributes [21].

As illustrated in Figure 2.3, PAT performs several important actions. The starting point is the identification of the attribute of interest which defines the purpose. This is followed by implementing suitable process monitoring techniques that measure signals of the process and convert the signals into data. Then process modeling uses the data of the process 
monitoring techniques as input to model the attribute of interest by employing e.g. MVDA. Mechanistic models also show the potential to serve as PAT tools [26]. The combination of process monitoring techniques and process models can be referred to as monitoring tools. Finally, the process control consists of a control model and a control system. The control model generates actionable commands, e.g. setpoints for CPPs, based on the output of the process model, e.g. for chromatographic separation [27, 28]. The control system then executes the commands causing the process to operate in the desired manner. The process control facilitates the $\mathrm{QbD}$ control strategy. Another element of PAT, not mentioned in Figure 2.3, is reporting and data management which enables continuous improvement of the process [9].

PAT enables a higher degree of process control and reduces the risk of batch failure. But monitoring tools capable to measure and predict critical quality and performance attributes in real-time, need to be developed.

\subsection{Examples of recombinant proteins}

The recombinant proteins investigated in this thesis, are described below. The list of biopharmaceuticals approved by the FDA in 2018 contains various recombinant antibodies, clotting factors, and hormones [5], underpinning the importance of focusing research efforts on proteins, such as monoclonal antibodies, insulin and factor VIII.

\section{Monoclonal antibody IgG}

The antibody IgG consists of two heavy and two light chains and has a molecular weight (MW) of approximately $150 \mathrm{kDa}$. Several subclasses exist of this monoclonal antibody. IgG is the most common antibody found in human blood [29]. Due to its high specificity, recombinant IgG can be used in diagnostics [30] and treatment of various diseases, such as cancer [31].

Commonly, this glycosylated protein is recombinantly produced in Chinese hamster ovary $(\mathrm{CHO})$ cell cultures. The purification platform of IgG usually comprises a capturing step (e.g. Protein A chromatography) and polishing steps, such as cation exchange (CEX) and anion exchange (AEX) chromatography. Virus removal and inactivation steps are included to fulfill regulatory requirements [32, 33]. During the 
purification of monoclonal antibodies, different conditions of the different process steps, e.g. elution at low $\mathrm{pH}$, can lead to antibody aggregation [34].

\section{Insulin}

Insulin is a relatively small protein with an MW of $6 \mathrm{kDa}$. This protein regulates glucose metabolism [35]. When patients do not produce enough insulin, insulin injections are required. Previously converted from pig insulin, nowadays insulin is produced recombinantly [36]. There are several production and purification processes established, usually involving refolding and a large number of process steps [37].

\section{Factor VIII}

Factor VIII is a blood clotting factor and is deficient in patients with hemophilia. Factor VIII is produced by isolating it from human blood serum or it can be recombinantly produced in mammalian cell cultures [38]. The protein has an MW of $166 \mathrm{kDa}$ and is glycosylated.

\section{Erythropoietin}

Erythropoietin (EPO) plays a key role in the production of red blood cells. Though intended to treat anemia, it might be more known as a doping agent. Recombinant EPO is produced by mammalian cell culture [39, 40]. This protein is heavily glycosylated which accounts for 40 to $50 \%$ of its MW [41]. The unglycosylated EPO has an MW of $18 \mathrm{kDa}$.

\section{Human growth hormone}

Human growth hormone stimulates growth during human development. Children with growth disorder or adults with growth hormone deficiency can be treated by administering human growth hormone [42]. Recombinant growth hormone (MW $22 \mathrm{kDa}$ ) is produced in bacteria cell cultures [43].

The above-mentioned recombinant proteins were used in this thesis to develop monitoring tools capable to support their respective downstream processes. 


\section{Chapter 3}

\section{Current practices and future possibilities in downstream process monitoring}

In Paper I of this thesis, existing analytical techniques are critically compared toward their potential as monitoring alternatives in downstream processing. The comparison is primarily based on bioanalytical relevance, sensitivity, selectivity and response time of the analytical techniques. The potential impact of implementing monitoring tools in downstream processing is evaluated as well. Importantly, before evaluating what analytical techniques or sensors could be used for monitoring, it is necessary to answer the question: What attributes should be monitored?

\subsection{Attributes of interest}

More attention has been paid to monitoring of upstream processing for optimizing the production of biopharmaceuticals to achieve a high-production titer [44]. Monitoring of DSP has become more important to reduce manufacturing costs and to tackle bottlenecks in downstream processing.

A major interest is to monitor the product throughout the purification train. Other attributes of interest are listed in Table 3.1 according to their relevance. The importance of impurity and process performance attributes varies depending on the product, production system and unit operation. While there are process-related impurities of high relevance 
(e.g. resin leakage), Table 3.1 underlines that various product-related impurities are more critical than process-related impurities or process performance attributes. The similarities between product and product-related impurities pose a challenge for downstream processing itself to achieve sufficient separation but also present a challenge for developing monitoring tools.

Table 3.1: Process- and product-related impurities, and process performance attributes of interest in DSP monitoring ordered by relevance (adapted from [45]).

\begin{tabular}{|c|c|c|}
\hline Process-related impurities & Product-related impurities & Process performance \\
\hline Resin leakage $\mathrm{e}^{* * *}$ & Insufficient glycosylation ${ }^{* * *}$ & Membrane integrity** \\
\hline Bioburden ${ }^{* * *}$ & Aggregates*** & Column recovery* \\
\hline $\mathrm{HCP}^{* *}$ & Precursors ${ }^{* * *}$ & Binding capacity over time* \\
\hline DNA $^{* *}$ & Cleaved forms ${ }^{* * *}$ & \\
\hline Endotoxins ${ }^{* *}$ & Oxidized forms $s^{* * *}$ & \\
\hline Introduced chemicals/ enzymes** & Different isoforms $s^{* * *}$ & \\
\hline Proteases ${ }^{* *}$ & Multimers ${ }^{* *}$ & \\
\hline Viruses ${ }^{* *}$ & Fragments ${ }^{* *}$ & \\
\hline USP media components ${ }^{* *}$ & Deamidation $^{* *}$ & \\
\hline
\end{tabular}

${ }^{* * *}$ highly important; ** important; * less important

\subsection{Monitoring techniques}

Monitoring techniques are methods to monitor the attribute of interest. Typically, a measuring system or sensor is incorporated and used to generate signals. Those signals can be univariate where only one variable is examined at a time [9]. Examples of such sensors widely used in bioprocessing are for temperature or $\mathrm{pH}$ measurements [46]. Those signals do not require any further data processing. Other sensors can measure physical properties or chemical compositions and provide multivariate signals which then are linked to process variables by a process model. Common multivariate sensors in USP and DSP are spectroscopic techniques such as infrared or UV/VIS spectroscopy [47-49].

To be able to control processes, measurements and modeling need to be performed in a timely manner [50]. Measurements can be performed off-line where a sample is removed from the process and the analysis may take several days. When at-line measurements are performed, a sample is removed as well, but the analysis only takes minutes and is usually performed in close proximity to the process [51]. On-line measurements are carried out directly in the process and usually take seconds [46]. 
In process chromatography, several on-line sensors, such as UV absorbance, $\mathrm{pH}$, conductivity or pressure sensors, are available to monitor the process (Table 3.2). While those univariate sensors are sufficient to run the chromatography step and can provide information on the product, they give insufficient information on process- and product-related impurities [52]. A chromatographic separation can be affected by variability in e.g. the biological feed material, the buffer composition or by changes in column performance over time. UV absorbance is used to monitor the column outlet and provides information on protein concentration and is the main source to take pooling decisions unless extensive off-line analytics are performed to quantify CQAs resulting in process downtime. UV absorbance is too unspecific to differentiate between product and product variants, especially if product variants occur in low abundance and have a similar absorbance profile.

To monitor the product and product-related impurities additional techniques are required. Ideally, those techniques provide rapid measurements, are non-destructive and do not require sample preparation. During the development of monitoring tools, those goals should be kept in mind but might not need to be realizable from the beginning.

Table 3.2: Summary of common on-line sensors in process chromatography, as well as sources of variability and critical process decisions.

\begin{tabular}{lll} 
Common sensors & Variability sources & Process decision \\
\hline UV absorbance & Biological feed material & Product pooling \\
pH & Buffer composition & \\
Conductivity & Column performance (over time) & \\
Pressure & & \\
& &
\end{tabular}

\subsubsection{Spectroscopy}

Spectroscopy is a powerful tool for monitoring of processes because of its fast response time, possible elimination of sample taking and its tendency to maintain sample integrity $[53,54]$.

Different spectroscopic techniques provide complementary information and can be used to monitor different attributes [55]. 
Depending on the wavelength regions of the electromagnetic spectrum, different information on the physical and electronic structure can be assessed when electromagnetic radiation interacts with matter, in our case proteins. The electromagnetic radiation is characterized by its energy. At lower wavelength ranges, such as in the UV or visible range, the energy is higher compared to the higher wavelength regions of the mid- and far-infrared range due to the indirect relationship of energy and wavelength [56]. The response time spans from seconds to a few minutes depending on the technique and setup. Usually, data analysis is employed to process the spectroscopic signals. The time to process or model, adds to the response time until the desired information is provided.

A variety of spectroscopic techniques can provide information on primary, secondary, tertiary or quaternary protein structure. This makes spectroscopy essential when investigating protein structure and an interesting option to explore its suitability for monitoring.

Spectroscopic techniques utilized for downstream process monitoring comprise, for example, UV/VIS, infrared, fluorescence and light scattering: UV/VIS spectroscopy has been demonstrated as a monitoring tool for quantification of a monoclonal antibody $(\mathrm{mAb})$ and its high and low molecular weight impurities in a CEX chromatography step [57] as well as in a mAb polishing step by variable pathlength UV/VIS spectroscopy [58]. Further, the column loading of a mAb onto a Protein A chromatography step has been controlled by UV/VIS spectroscopy [59]. Fourier transform infrared (FTIR) spectroscopy has been used to monitor a mAb product in several downstream process units, as well as aggregates and host cell proteins at higher concentrations [60, 61]. As an in-line monitoring tool, FTIR distinguished proteins in mixtures as well as process-related impurities, such as Triton [62]. Also, cleaning-in-place (CIP) of an affinity chromatography column has been monitored by FTIR [63]. Fluorescence spectroscopy has been applied for at-line monitoring of a hydrophobic interaction chromatography step to take pooling decisions and separate correctly folded from misfolded protein [64]. Light scattering has been employed to monitor protein refolding and aggregation of a fusion protein [65] and to take pooling decisions and separate aggregates from the $\mathrm{mAb}$ product [66].

\section{Multi-wavelength fluorescence spectroscopy}

Multi-wavelength fluorescence spectroscopy can be employed to obtain information on protein conformation. Of the three aromatic amino acids 
(tryptophan, tyrosine, and phenylalanine) contributing to the intrinsic fluorescence of proteins, tryptophan residues usually dominate the signal $[67,68]$. Tryptophan residues also show a high sensitivity to their local chemical environment $[69,70]$. When structural changes that affect the local environment of tryptophan residues, occur in a protein, those would be detectable by fluorescence spectroscopy. This makes multi-wavelength fluorescence spectroscopy an excellent candidate to monitor product variants, structures slightly different than the product. In multi-wavelength fluorescence spectroscopy, the protein sample is excited at a range of excitation wavelengths and the emission from the sample is scanned at a higher wavelength range.

Figure 3.1 depicts a typical fluorescence signal of a protein. In Figure 3.1a, the original signal is shown which also includes Rayleigh and Raman scattering. Data preprocessing can be applied to remove the scattering and interpolate the deleted data to reveal the entire fluorescence signal (Figure 3.1b). With an excitation maximum of $280 \mathrm{~nm}$ and an emission maximum of approximately $350 \mathrm{~nm}$, the tryptophan residues of this protein are the main contributor to the fluorescence signal. To extract more information from the fluorescence signal, MVDA needs to be applied which will be discussed in the following chapter.

a

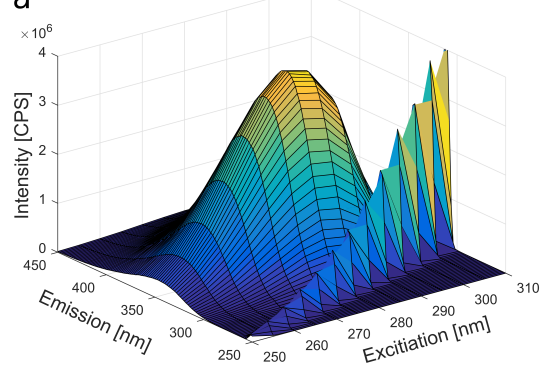

b

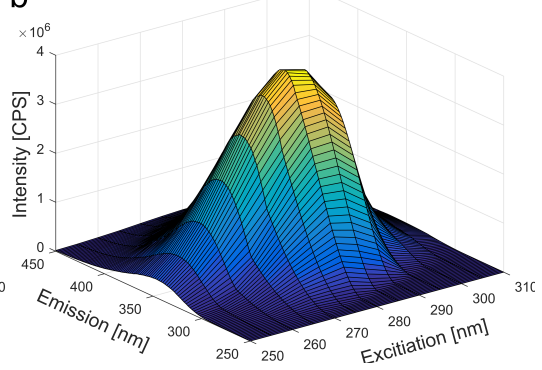

Figure 3.1: Example of multi-wavelength fluorescence signal a) original b) preprocessed to remove Raman and Rayleigh scattering.

\subsection{The soft sensor concept for downstream process monitoring}

A soft sensor combines one or several hardware sensors that deliver data, with an estimator which models the data to derive new information. The hardware sensor is placed in e.g. the outlet stream of a bioprocess unit operation to perform on-line measurements. The delivered signals are 
converted to data and the data are then processed by a 'software' model to estimate variables (Figure 3.2).

The idea is to estimate process variables that are difficult to measure directly, by modeling more easily accessible on-line data which can be linked to the desired process variables $[71,72]$.

Different kinds of hardware sensors are mentioned in section 3.2 and in Paper I. The key point is that the measurements need to take place rapidly and continuously. Then the model can estimate the variables in a timely manner, capture occurring changes and can facilitate process decisions.

The estimator can be an advanced mechanistic model, MVDA, or a combination of both to estimate variables [73-75]. Both approaches, mechanistic and data-driven modeling are discussed in the next chapter. Developing soft sensors for downstream processing requires a response time of seconds for the sensor and the model due to the fast nature of e.g. chromatographic elutions. In upstream processing response times of minutes or more might be acceptable depending on the growth of the host cell organisms and the rapidness of occurring changes.

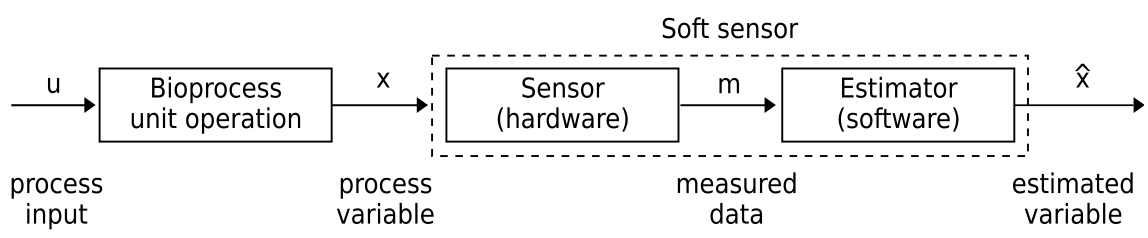

Figure 3.2: The soft sensor concept illustrated at the outlet of a bioprocess unit operation. The soft sensor contains one hardware sensor whose measured data is modeled by an estimator to estimate a process variable. (adapted from [76]).

\subsection{Impact of monitoring on quality and process economy}

The different stages of biopharmaceutical development can benefit from process monitoring and modeling [44]. During early process development, parameter interactions can be characterized and their impact on the product can be monitored when evaluating alternative production and purification strategies.

In the later stage, the implementation of monitoring tools can facilitate achieving high product quality and yield. By providing more information 


\subsection{IMPACT OF MONITORING ON QUALITY AND PROCESS ECONOMY}

about the process, process understanding can be gained, and process control strategies enabled [77].

During manufacturing, process operations can become more efficient, process downtime can be reduced, and the risk of batch failure can be decreased which may improve the production economy. However, the initial investment costs of monitoring techniques and the operation and maintenance costs, require financial commitment [53].

Moreover, implementing monitoring tools during biopharmaceutical development and manufacturing is strongly supported by regulatory authorities, as highlighted in the PAT initiative. When monitoring tools are used to take process decisions, regulatory approval of the methodology is required. This might hamper the implementation of monitoring tools into already approved processes but can still provide additional process understanding and support for troubleshooting.

For the development of new biopharmaceuticals, monitoring tools could be developed in parallel and the approval for the process could be filed together with the approval of the monitoring tool.

This thesis focuses on developing monitoring tools for downstream processing of biopharmaceuticals.

Product variants were identified as attributes of interest through the evaluation in Paper I and discussions with industrial collaborators. Different biopharmaceuticals and their respective product variants were studied.

Monitoring tools based on mechanistic modeling and data-driven modeling of multi-wavelength fluorescence spectral data were developed to provide additional means for enabling Quality by Design.

Each monitoring tool was demonstrated at one or several unit operations of the downstream process of the respective biopharmaceutical. 
CHAPTER 3. CURRENT PRACTICES AND FUTURE POSSIBILITIES IN DOWNSTREAM PROCESS MONITORING 


\section{Chapter 4}

\section{Modeling approaches to enhance downstream processing}

In this chapter, the fundamentals of the different modeling approaches which are used in this thesis, are described. The mechanistic model approach is utilized in Paper II. Paper III and IV rely on a data-driven approach, in particular, PARAFAC.

\subsection{Mechanistic models}

Mechanistic models describe underlying mechanisms and phenomena occurring in the system of interest. Those mechanisms can be physical, chemical or biological. For the model, assumptions are made, interactions identified, and a complex system is simplified to describe it by mathematical equations. Mechanistic models require to understand the behavior of each elementary part contributing to the system.

\subsubsection{Chromatography models}

In the case of modeling chromatography, the mass transfer through the column and the interaction with the stationary phase need to be described.

The mass transfer specifies the transport of the solute contained within the mobile phase through the stationary phase where the solute disperses axially and diffuses into the pores of the stationary phase depending on their size. Adsorption and desorption interactions between 
the solute in the mobile phase and the stationary phase need to be described to assess the binding and elution behavior of the solute.

\section{Mass transfer}

The elementary parts contributing to mass transfer are the convective flow through the column, axial dispersion, which is the diffusion along the axial column dimension, mass transfer through the external film of the mobile phase surrounding the stationary phase and diffusion of the solute within the stationary phase's particle pores [78, 79]. There are various models describing chromatography systems. Simpler models only consider convective flow whereas more advanced models consider additional physical terms.

The question arises how detailed the model needs to be, to obtain a good approximation of the real system? In principle the simplest approximation representing the system adequately is desirable.

\section{Adsorption}

The adsorption term in a chromatography model describes the interactions of ligands of the stationary phase with the solute in the mobile phase. In the simplest description, a linear relationship between the solute concentration in the stationary phase and the solute concentration in the mobile phase is assumed [80]. This assumption of a large number of free binding sites is only accurate when low amounts of solute are loaded onto the chromatography column. At high amounts, the saturation of the stationary phase needs to be considered. When more than one solute is modeled, the competition for binding sites needs to be included. The adsorption and desorption of the solute also depend on the mobile phase modifier, such as $\mathrm{pH}$ or counter ions concentration, depending on the kind of chromatography system used. To approximate the adsorption term, one usually relies on experimentally correlated equations due to the complexity of protein adsorption $[80,81]$.

\subsubsection{Modeling reversed phase chromatography}

In this thesis, a kinetic dispersive model with a modified Langmuir isotherm was used to monitor the reversed phase chromatography (RPC) separation of insulin and two product variants (Paper II). 
The model is based on previous work by Degerman, Jakobsson and Nilsson [82] and describes convective flow, axial dispersion, and adsorption kinetics. The mass transfer can be expressed as follows:

$$
\frac{d c_{i}}{d t}=D_{a x} \frac{\partial^{2} c_{i}}{\partial x^{2}}-\nu_{a p p} \frac{\partial c_{i}}{\partial x}-\frac{1-\epsilon_{c}}{\epsilon_{c}+\left(1-\epsilon_{c}\right) \epsilon_{p}} \frac{\partial q_{i}}{\partial t}
$$

where $c_{i}$ is the concentration of component $i$ within the mobile phase, $D_{a x}$ is the dispersion coefficient and the Peclet number $\mathrm{Pe}$ (Equation 4.2) is used to calculate $D_{a x}$. $\nu_{a p p}$ represents the apparent interstitial velocity, $\epsilon_{c}$ is the bed porosity, $\epsilon_{p}$ is the particle porosity of the column and $q_{i}$ is the concentration of component $i$ in the stationary phase. $t$ represents time and $x$ describes the axial coordinate of the column.

$$
P e=\frac{\nu_{a p p} d_{p}}{D_{a x}}
$$

where $d_{p}$ is particle diameter of the stationary phase.

The adsorption is described by a modified Langmuir isotherm (Equation 4.3)

$$
\frac{d q_{i}}{d t}=k_{k i n}\left(c_{i} H_{i} \exp \left(\gamma_{i} c_{E t O H}\right)\left(1-\sum_{i=1}^{N} \frac{q_{i}}{q_{\max , i}}\right)-q_{i}\right)
$$

where $k_{k i n}$ is the adsorption rate constant, $H_{i}$ is the Henry's constant and $\gamma_{i}$ is the mobile phase modifier of component $i, c_{E t O H}$ is the concentration of the ethanol modifier and $q_{\max , i}$ is the maximal concentration of component $i$ in the stationary phase.

Commonly, concentration differences along the radial dimension of the column are neglected and boundary conditions, such as Robin and von Neumann conditions [80], are set for the column inlet and outlet. Initial conditions usually assume the mobile phase concentration of the equilibration buffer and no adsorption of protein at the start of the simulation.

Some parameters easily can be experimentally determined, extracted from literature or based on previous experience. Examples are bed and particle porosity or maximum binding capacity. Other parameters need 
to be fitted to experimental data during model calibration to assure that the model approximates the real system accurately.

The model can be solved by discretizing the partial differential equations into a set of ordinary differential equations (ODEs) which can be solved by an ODE solver. The structure of the mechanistic model to calibrate the model parameters is depicted in Figure 4.1. The model contains the mass transfer and adsorption isotherms which incorporate the model parameters that need to be determined by an optimization algorithm. The ODE solver solves the isotherms (Equation 4.1 and Equation 4.3). Then an optimization algorithm, e.g. least squares curve fitting, compares the modeled response with the experimental data, usually the UV absorbance signal, and minimizes their difference by adjusting the model parameters. For the reversed phase chromatography model, the Henry's constant $H_{i}$ and the mobile phase modifier $\gamma_{i}$ are determined by least squares curve fitting.

\begin{tabular}{|l|l|}
\hline $\begin{array}{l}\text { Experimental } \\
\text { data } \\
\text {-UV absorbance } \\
\text { chromatogram } \\
\text {-protein } \\
\text { concentrations }\end{array}$ & $\begin{array}{l}\text { Least squares curve fitting } \\
\text {-fits modeled and experimental data by adjusting model parameters }\end{array}$ \\
$\qquad \begin{array}{l}\text { Response } \\
\text {-extracts modeled response }\end{array}$ \\
$\begin{array}{l}\text { ODE solver } \\
\text {-solves mass transfer and adsorption isotherm } \\
\text {-models protein } \\
\text { concentrations }\end{array}$ \\
\hline $\begin{array}{l}\text { Model } \\
\text {-mass transfer } \\
\text {-adsorption isotherm } \\
\text {-incorporates model parameters }\end{array}$ \\
\hline
\end{tabular}

Figure 4.1: Structure of mechanistic model to calibrate model parameters to experimental data (adapted from [83]).

\subsubsection{Model sensitivity}

After the calibration of the mechanistic model, the model parameters are determined. The model relies on those fixed values as well as the other parameter values obtained from literature, experience, and experiments to not change over time.

But the chromatographic separation itself can be influenced by changes in protein concentration, buffer composition or temperature [84, 85], to name a few. System errors or human errors can impact the experimental part which can lead to a discrepancy between model and experiment. Model parameter uncertainty can be due to experimental uncertainties or due to the calibration of the model [86]. The model performance can be 
studied with regard to parameter uncertainty by analyzing the model's sensitivity. The idea is to identify the impact of parameter uncertainty on the model outcome and identify which parameters and interactions of parameters have the greatest effect on the model performance [87].

This can be achieved by a full or fractional factorial analysis where the parameters investigated are systematically varied within a predefined range $[88,89]$. A full factorial analysis investigates all possible combinations of parameters at set parameter levels. Usually, two or three levels are investigated for each parameter [90]. A 2-level full factorial design of three parameters can be depicted as in Figure 4.2. The level '-1' could, for example, correspond to a parameter's value minus $5 \%$ and the level ' 1 ' could correspond to the parameter's value plus $5 \%$. Total number of simulations for studying $k$ factors corresponds to $2^{k}$, therefore eight simulations would need to be conducted for the mentioned example.

After the mechanistic model simulated all possible combinations of levels for all parameters investigated, the impact of each parameter and parameter interaction on the model performance can be ranked. The results of the sensitivity analysis of the reversed phase chromatography model are presented in the next chapter.

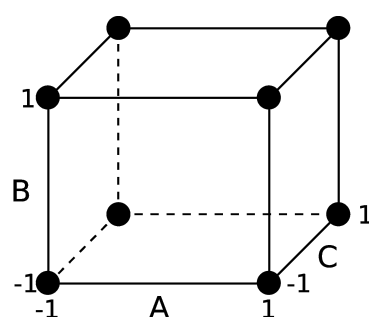

Figure 4.2: Illustration of 2-level full factorial design with three parameters A, B, C.

\subsection{Data-driven models}

Data-driven models fit a generic model to measured data by describing the input-output relationship. Those models find structure in huge datasets, obtained by e.g. sensor measurements, and correlate it with reference data. The models are often used to estimate attributes that are not easily measured directly but rely on data that can be correlated to the desired attribute. 


\subsubsection{Multivariate data analysis}

Data are multivariate when multiple variables are measured, at multiple time points or multiple samples. An example of univariate data is the UV absorbance measurement at a single variable e.g. at the wavelength of $280 \mathrm{~nm}$. The data becomes multivariate when instead measuring an absorbance spectrum at multiple wavelengths.

More information can be obtained from accessing multivariate data simultaneously than from analyzing each variable individually [91, 92].

MVDA extracts relevant information from large datasets by reducing the data. Hidden patterns and parameter relationships can be identified. Variables containing similar information are compressed and by separating data with relevant information from data without relevant information, noise can be reduced $[92,93]$.

MVDA can be used for classification or quantification. Classification is a qualitative assessment that identifies groups of similar observations. Principal component analysis (PCA) is commonly used for classification. When the observations are correlated with reference data e.g. concentration data, then principal component regression (PCR) and partial least squares (PLS) regression can be useful tools [93].

Here, MVDA is employed for analyzing data from process monitoring techniques to enhance PAT. Other areas of use are e.g. early fault detection, quality control, identification of structure-propertyrelationships or image analysis [93].

\subsubsection{Principal component analysis, principal component regression and partial least squares regression}

Principal component analysis transforms the given dataset into a new coordinate system and finds new components that maximize the variance. To simplify, an absorbance spectrum measured at two wavelengths can be pictured (Figure 4.3a). Then the spectrum is transformed into a new coordinate system where each coordinate axis represents a wavelength. When K-wavelengths of a spectrum have been measured, the spectrum is transformed into a K-dimensional coordinate system. In the example, the spectrum with two wavelengths is transformed into a two-dimensional coordinate system (Figure $4.3 \mathrm{~b}$ ). If spectra were acquired for several samples, a data cloud in the $\mathrm{K}$-dimensional coordinate system is obtained (Figure $4.3 \mathrm{c}$ ). The main part of PCA is to find new components that describe this data cloud. The first component captures the maximal variation, the second component is 
orthogonal to the first one and is identified in the direction of second biggest variation (Figure 4.3d) [93]. Also, additional principal components are orthogonal to the preceding ones. Significant systematic variation in the data and random noise or measurement errors are described by various principal components. But the main information in the variables (wavelengths in the example) is expressed in the first couple of principal components. Whereas principal components describing noise are eliminated, reducing the dimensionality of complex problems. The PCA model can be expressed as follows:

$$
X=T P^{T}+E
$$

where $X$ is the original data, $T$ represents the score matrix, $P^{T}$ is the transposed loading matrix and $E$ is the residual matrix [94].

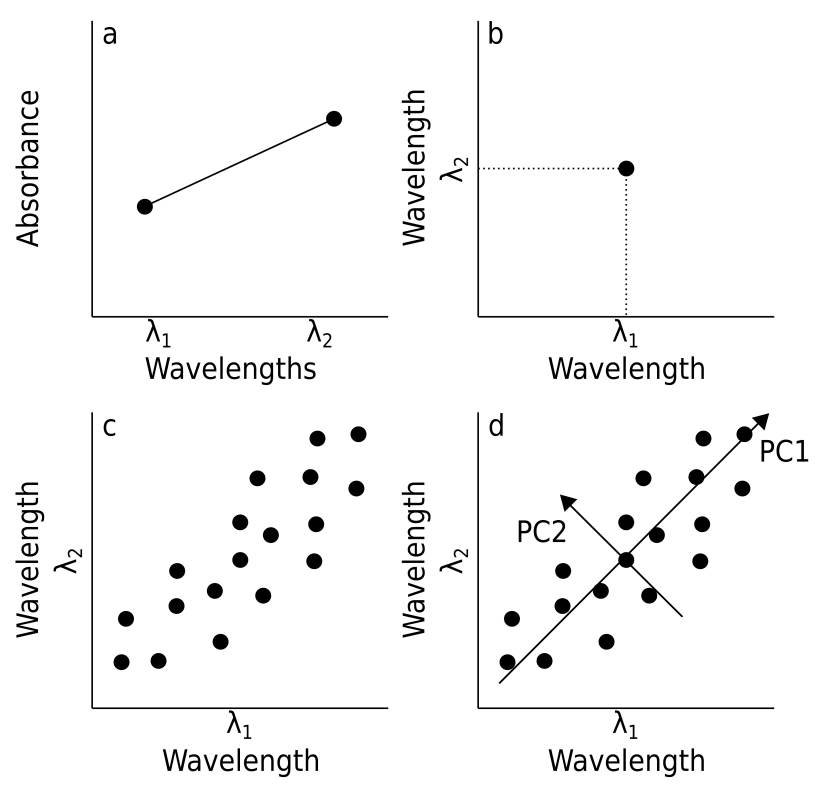

Figure 4.3: Simplification of PCA principle. a) Absorbance spectrum measured at two wavelengths $\lambda_{1}$ and $\lambda_{2}$. b) Spectrum transformed into one data point in two-dimensional space which is defined by the two measured wavelengths. c) Additional spectra of dataset transformed into two-dimensional space. d) The main part of PCA where the principal components (PCs) are identified in direction of biggest variation in the dataset (adapted from [95]).

The original data $X$ is of the size $I \mathrm{x} J$ where $I$ represents the number of samples and $J$ is the number of variables. The scores are new coordinate 
values which are obtained by projecting each datapoint of the K-dimensional space onto the principal component. The loadings describe the importance of each variable to approximate $X$. The matrix product of $T P^{T}$ models the structure of the original data $X$ and $E$ contains non-relevant information, such as noise [92, 93].

To obtain a useful model, data is often pre-treated. For example, the removal of background signals or scattering might be necessary.

PCA forms the basis of other models such as PCR or PLS regression which are quantitative models allowing the prediction of e.g. sample concentrations based on the samples' absorbance spectrum.

In PCR, PCA is performed first and then the PCA scores are correlated to the dependent reference data (Equation 4.5) by estimating the regression coefficient (Equation 4.6).

$$
Y=\beta T
$$

where $Y$ represents the reference data, $\beta$ is the regression coefficient and $T$ is the score matrix of the PCA which might be extended with a column of ones if an intercept is estimated.

$$
\hat{\beta}=T^{T} Y\left(T^{T} T\right)^{-1}
$$

(Equation 4.6)

where $\hat{\beta}$ is the estimated regression coefficient, $T^{T}$ is the transposed score matrix (including a column of ones for the intercept) [92].

Comparing PCR to PLS regression, the information in $Y$ is not actively used in PCR. In PLS regression, the relation between the two data matrices, $X$ and $Y$, is modeled. PLS regression does not use principal components that are not relevant for $Y$. By maximizing the covariance between the score vectors $T$ and $U$ (Equation 4.7 and Equation 4.8), the impact of irrelevant variation in $X$ is limited [96].

In PLS regression, PCA is performed simultaneously for $X$ and $Y$ while aligning both models.

$$
\begin{aligned}
& X=T P^{T}+E \\
& Y=U C^{T}+F
\end{aligned}
$$

where $X$ and $Y$ are the original input and reference data. $T$ and $U$ are the score matrices, $P^{T}$ and $C^{T}$ are the transposed loading matrices and $E$ and $F$ are the residuals [93]. 
PLS regression has a stronger tendency to overfit than PCR [96]. For each model, it is essential to evaluate the model, to find the correct number of components and to perform model validation. This will be addressed in section 4.3.

\subsubsection{Parallel factor analysis}

PCA, PCR, and PLS require the original data to be two-dimensional (size $I \times J)$. When the original data are of higher dimension, the data can be unfolded to be two-dimensional, but this might lead to the loss of information and less interpretable models [97]. Otherwise multi-way algorithms can be employed which are capable to handle three- or higher dimensional data.

PARAFAC is an example of a multi-way algorithm and represents a generalization of PCA [97].

Multi-way data are, for example, multi-wavelength fluorescence spectra measured for several samples. The data can be arranged in a data cube of the size $I \times J \times K$ where $I$ represents the number of samples, $J$ the emission and $K$ the excitation wavelengths. PARAFAC decomposes this three-way data cube into one score vector and two loading vectors for each component. A two-component PARAFAC model is illustrated in Figure 4.4 and can be expressed as follows:

$$
x_{i j k}=\sum_{n=1}^{N} a_{i n} b_{j n} c_{k n}+e_{i j k}
$$

where $x_{i j k}$ are the elements of the original data $X$ arranged in a three-way array. $a_{i n}, b_{j n}, c_{k n}$ are the elements of the score matrix $A$ and the loading matrices $B$ and $C$, respectively. $n$ representing the number of components and $e_{i j k}$ represents the elements of the residual matrix $E$.

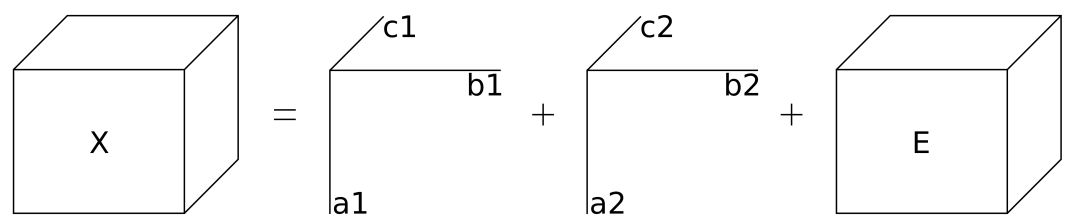

Figure 4.4: Illustration of two-component PARAFAC model [97].

The PARAFAC scores contain relative concentration information and can be further used in a regression model, similar to PCR, which is one way of obtaining quantitative information. 
PARAFAC can resolve highly convolved signals and elucidate accurate estimates of the underlying physical phenomena when the right number of components has been chosen [92]. Multi-wavelength fluorescence spectra of proteins are an example of overlapping signals due to the overlapping emission ranges of the aromatic amino acids.

In this thesis, PARAFAC was employed to reveal underlying physical phenomena of multi-wavelength fluorescence spectra to elucidate emission shifts of biopharmaceuticals occurring upon product variant formation (Paper III and IV).

To obtain a sufficient model, it is essential to choose the correct number of components. This is important for all data-driven models. For PARAFAC the estimated loadings can be visually inspected and compared to expected underlying physical phenomena. For different models, slightly different diagnostic tools are available to determine the correct number of components. Generally speaking, variance explained by each component should be considered and the model should be validated, either by cross-validation or preferably with an independent dataset.

\subsection{Model validation and limitations}

To evaluate if the calibrated model is an accurate approximation of the real system, the model has to be validated. In the case of data-driven models, cross-validation can be performed, where part of the dataset is left out of the model calibration and then predicted. If the input data which will be predicted in the future, are expected to be highly similar to the calibration data, cross-validation might be suitable. But biological systems usually display a fair amount of variation. To generate more robust models, validation with independent data is preferred.

Residuals and model errors between predicted and actual response can be calculated to evaluate the model, e.g. the root mean square error of calibration (RMSEC) and prediction (RMSEP). The goodness of fit $\mathrm{R}^{2}$, indicating how well the model represents the calibration data, can be calculated as well as the goodness of prediction $\mathrm{Q}^{2}$ which shows how well the model can predict new data.

To know if a model can be trusted, model validation and knowing the model's limitations is important. Models are desired to be simple approximations of the real system because increased model complexity may lead to less intuitive models, longer computation times and might be 


\subsection{A COMPARISON OF MECHANISTIC AND DATA-DRIVEN MODELS}

more error-prone. But by simplifying, information is left out and one needs to be sure that no essential information is missing. Models might be developed for test systems portraying already a simplification of the real system. This can lead to a model not being able to account for 'unexpected' variation, such as an unaccounted analyte. Simplifications such as a homogeneous concentration in the radial column dimension or the assumption that no conformational changes of proteins occur in the column are common when modeling chromatography. But by oversimplifying the mass flow to only the convective flow or assuming a linear relationship between solute concentration in mobile and stationary phase, the model might be inefficient. It has to be decided which simplifications are acceptable.

The uncertainty present in the measured data, e.g. for HPLC the error from injection, separation, detection and signal processing add up to the total error of the measured data and contributes to the error of the model as well [98]. Model uncertainty can be addressed by analyzing the sensitivity of the model or using large datasets for calibration.

How 'good' a model is, also depends on its intended use. Models can be evaluated according to their capability to capture the relevant information of a real system and regarding their accuracy within a defined range. Model complexity and computational time might also be considered.

\subsection{A comparison of mechanistic and data-driven models}

To summarize, mechanistic models approximate a system by describing its underlying mechanisms and phenomena with mathematical equations (Figure 4.5). Data-driven models are fitted to describe input-output relationships, typically without their parameters having a physical meaning. PARAFAC represents an exception of the data-driven models since its components can identify underlying physical phenomena when the correct number of components is identified.

Contrary to data-driven models where the number of components or model parameters is not fixed, the number of model parameters is predetermined in mechanistic models. In both cases, the model parameters are estimated from calibration data (or are based on prior knowledge for mechanistic models). Mechanistic models are often described by ordinary or partial differential equations to approximate a system that changes in regard to time and space. The data-driven model 
in this thesis relies on a static model correlating input and output.

Data-driven models require broad and representative datasets for model calibration because they can only predict within the ranges they have been calibrated. Because mechanistic models describe physical phenomena, those models can be extrapolated if the physical phenomena are accurately described [99, 100].

Data-driven models benefit from large datasets, whereas a small number of experiments can be sufficient to estimate the mechanistic model parameters. Usually, the computation of data-driven models is less time consuming than mechanistic models.

Mechanistic and data-driven approaches can also be combined to benefit from each of their advantages [101]. As illustrated in Figure 4.5, the mechanistic model does not require input data after the model parameters have been calibrated. In this thesis, the protein concentrations of the feed material were provided to the mechanistic model nevertheless because of the concentration variation in the feed. The monitoring tools which were developed in this thesis, incorporate mechanistic and data-driven approaches and are presented in the next chapter.

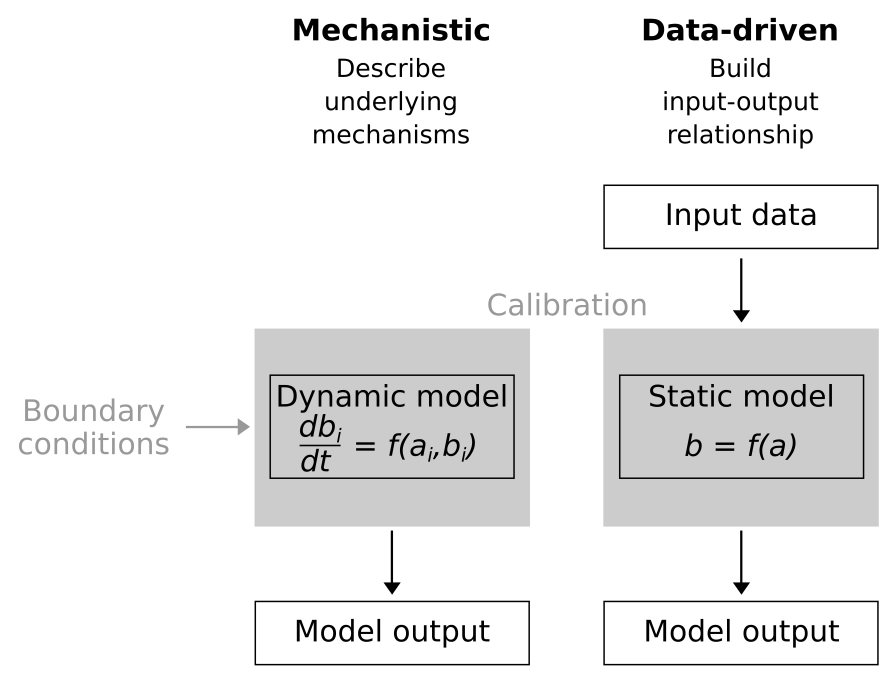

Figure 4.5: Comparison of mechanistic and data-driven modeling approaches as used in this thesis. 


\section{Chapter 5}

\section{Novel tools based on existing monitoring and modeling approaches to monitor downstream processing}

In this thesis, two monitoring tools have been developed. One is based on a mechanistic model approach and has been implemented for a reversed phase chromatography polishing step of insulin (Paper II). The other monitoring tool relies on fluorescence spectroscopy coupled with PARAFAC to monitor the product and variant and has been demonstrated for several biopharmaceuticals (Paper III and IV).

Monitoring tools of chromatographic separations aim to facilitate pooling decisions. Model-based pooling has been compared to current practice pooling and showed a yield increase while maintaining purity (Paper II).

For the applicability of these monitoring tools in the biopharmaceutical industry, their transferability to other products and processes needs to be demonstrated as well (Paper IV).

Both monitoring tools are critically compared regarding the criteria established in Paper I.

\subsection{Mechanistic model-based monitoring}

Mechanistic models can provide valuable insight into protein separation that can support process development. Mechanistic models allow the 
simulation of process running conditions to identify optimal operation which can result in saving experimental time and cost.

In Paper II is demonstrated, how to employ mechanistic models for monitoring of a chromatographic separation in a bioprocess and the concept is illustrated in Figure 5.1. The mechanistic model is calibrated to concentration data obtained from specific quality control analytics, instead of calibration to the unspecific UV absorbance data. This allows the simulation of low abundant and low concentrated product variants. The variation in biological feed material is addressed by providing the inlet concentration to the model. The model predicts the concentration of the product and its variants which subsequently can be used to take critical pooling decisions.

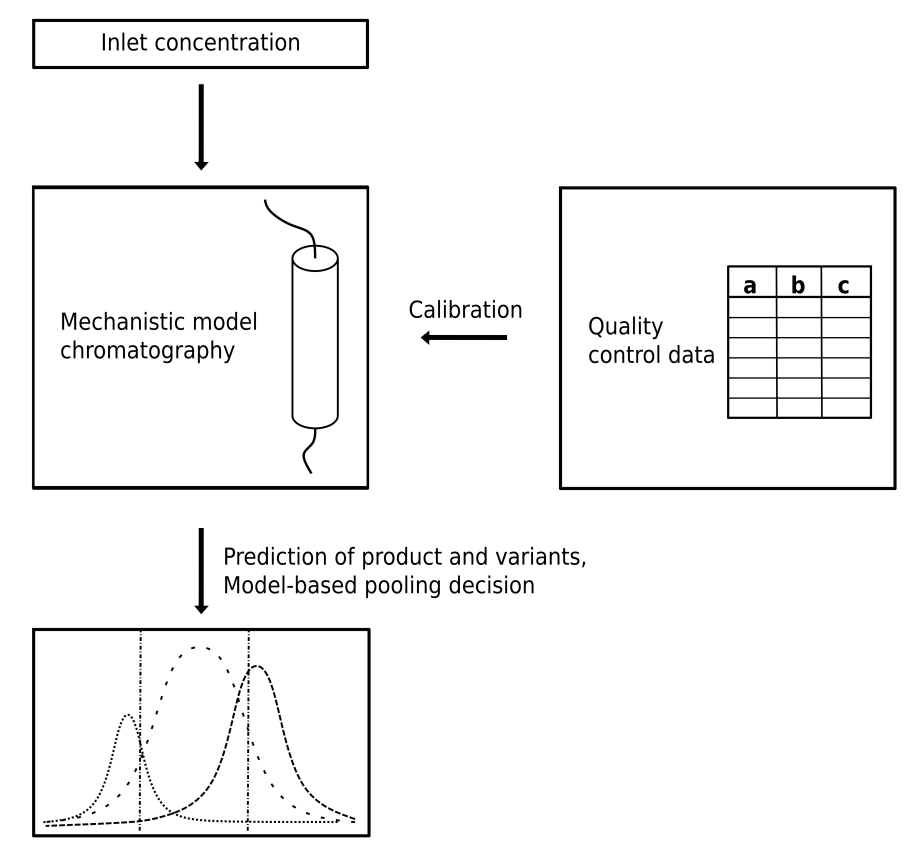

Figure 5.1: Concept of mechanistic model-based monitoring.

The mechanistic model-based monitoring tool was developed for an industrial reversed phase polishing step of insulin. This step aims to remove variant forms of insulin that are structurally very close to the product. The UV Absorbance at $280 \mathrm{~nm}$ displayed no clear shoulders in that purification step (Figure 5.2a), solely a peak tail hints to the elution of variants. 


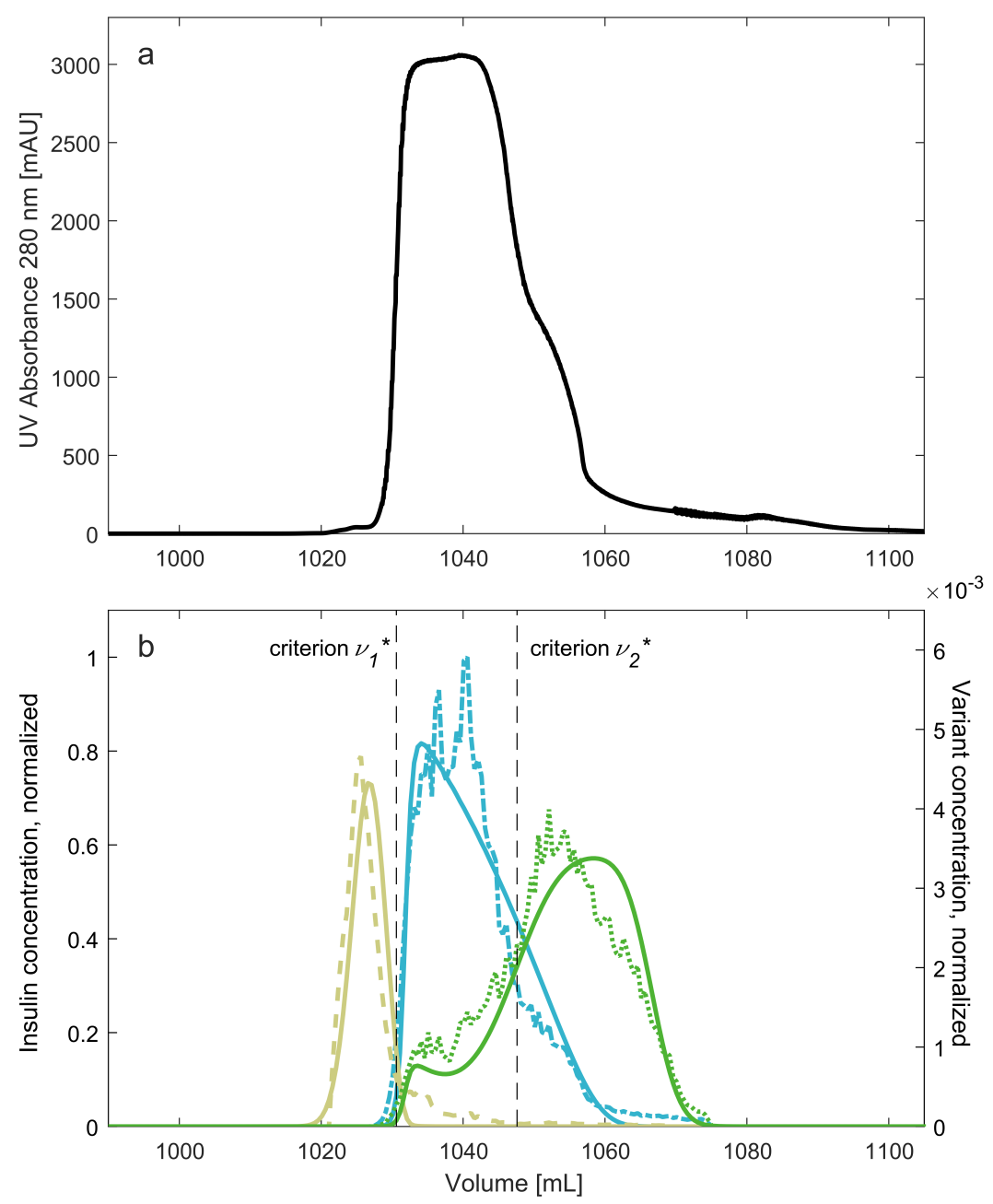

Figure 5.2: Validation run with a) UV Absorbance at $280 \mathrm{~nm}$ and b) mechanistic model-based monitoring. The modeled (solid lines) and experimental (dashed/ dotted lines) elution profiles are compared for insulin (blue), Variant A (yellow) and Variant B (green). The model-based pooling decision is indicated $\left(\nu_{1}^{*}\right.$ and $\left.\nu_{2}^{*}\right)$ [83].

The model was simultaneously calibrated to quality control data from three purification runs to estimate the model parameters, as described in Chapter 4. To validate the accuracy of the model, the elution profiles of insulin and its two variants were simulated and compared to the experimental data of the independent validation run (Figure 5.2b). The elution profile of insulin is well captured. The peak maximum of 
Variant A is skewed while the peak base is well predicted. The experimental and modeled elution start and end of Variant B coincide while its shoulder and main peak are partly underestimated.

The goal of implementing mechanistic model-based monitoring is to take pooling decisions which can be based on objective functions [102, 103]. Current practice when performing pooling decisions relies on extensive and time-consuming off-line quality control analytics. Furthermore, safety margins are applied to the established pooling criteria. This assures that if variation occurs, the pooled product will still meet its purity requirements but limits the product yield.

The pooling decisions taken by the mechanistic model-based monitoring tool are indicated in Figure $5.2 \mathrm{~b}$ and compared to current practice pooling. A yield increase of $4.7 \%$ was revealed [83]. By relying on mechanistic model-based monitoring, process downtime can potentially be decreased, and the product yield can be increased while ensuring product purity.

Chromatography can be affected by variation e.g. in buffer compositions or protein concentrations. Experimental variation might affect the mechanistic model describing the system. Therefore, a sensitivity analysis should be performed to identify how parameter uncertainty influences the model response.

The uncertainties of loading concentration of insulin, Variant A and Variant $\mathrm{B}$ as well as the ethanol concentration in the equilibration and elution buffer were investigated. Furthermore, uncertainties in the flow rate, column length, and bed porosity were considered. The investigated parameters are referred to as $\Theta_{1-8}$ (Table 5.1). Variations of $\pm 1 \%$ of the set values were investigated for each parameter. The model response effect when the parameters were varied, was compared to the model response effect at set values. The sum of squared error served as response effect for the full factorial analysis.

The response effect is higher at high level than at low level for the parameters $\Theta_{1}$ and $\Theta_{6}$ (Figure 5.3). Reversely, the effect is higher at low level than at high level for parameters $\Theta_{5}, \Theta_{7}$ and $\Theta_{8}$. For the parameters $\Theta_{2}$ to $\Theta_{4}$ no change in effect was observed between highand low-level parameter settings. In other words, increased insulin concentration and increased ethanol concentration in the elution buffer decrease the accuracy of the model. Also, lower ethanol concentration in the equilibration buffer, decreased column length and a lower bed porosity contribute to model inaccuracy. 
Table 5.1: Parameters investigated for model sensitivity analysis.

\begin{tabular}{clll} 
Abbreviation & Parameter & Unit & Set value \\
\hline$\Theta_{1}$ & Insulin loading concentration & $\mathrm{mol} / \mathrm{m}^{3}$ & 0.09 \\
$\Theta_{2}$ & Variant A loading concentration & $\mathrm{mol} / \mathrm{m}^{3}$ & $7.10 x 10^{-4}$ \\
$\Theta_{3}$ & Variant B loading concentration & $\mathrm{mol} / \mathrm{m}^{3}$ & $1.77 x 10^{-4}$ \\
$\Theta_{4}$ & Flow rate & $\mathrm{m}^{3} / \mathrm{s}$ & $2.17 x 10^{-8}$ \\
$\Theta_{5}$ & Ethanol concentration in equilibration buffer & $\mathrm{w} / \mathrm{w}$ & 0.08 \\
$\Theta_{6}$ & Ethanol concentration in elution buffer & $\mathrm{w} / \mathrm{w}$ & 0.54 \\
$\Theta_{7}$ & Column length & $\mathrm{m}$ & $232 x 10^{-3}$ \\
$\Theta_{8}$ & Bed porosity & - & 0.33 \\
& & & \\
\hline
\end{tabular}
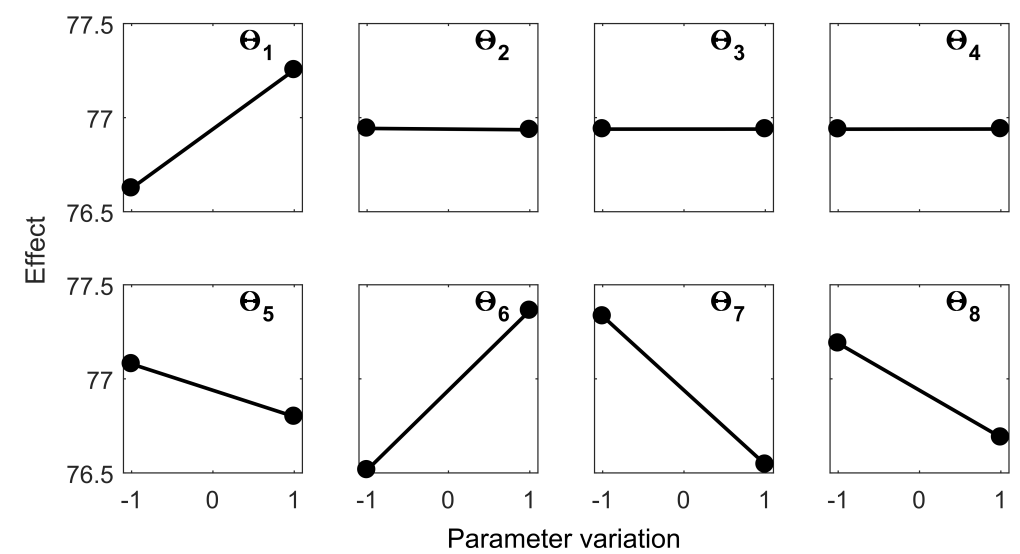

Figure 5.3: Main effect plots of parameters $\Theta_{1}$ to $\Theta_{8}$ with sum of squared error as response effect.

The main effects only provide information on each individual parameter. But a combination of parameter uncertainties could impact the model as well (Figure 5.4). Parameter interactions occur when the effect of one parameter depends on the level of the other parameter [90]. Parameter interactions were observed for parameter $\Theta_{1}$ interacting with $\Theta_{5}, \Theta_{6}, \Theta_{7}$ and $\Theta_{8}$. Furthermore, parameter $\Theta_{5}$ interacted with $\Theta_{6}, \Theta_{7}$ and $\Theta_{8}$. Parameter $\Theta_{6}$ interacted with $\Theta_{7}$ and $\Theta_{8}$. Also, parameter interactions were observed between the parameters $\Theta_{7}$ and $\Theta_{8}$. The interaction between parameter $\Theta_{6}$ and $\Theta_{7}$, namely ethanol concentration in elution buffer and column length, had by far the most impact on the model (Figure 5.5). Further interactions with a considerable effect were between parameters $\Theta_{5}$ and $\Theta_{7}$, ethanol concentration in equilibration buffer and 
column length; between parameter $\Theta_{5}$ and $\Theta_{6}$, ethanol concentration in equilibration and elution buffer; as well as between $\Theta_{7}$ and $\Theta_{8}$, column length and bed porosity. Those interactions affected the model far more than any individual parameter. Third-order and higher-order interactions were also investigated but did not display any significant effect.

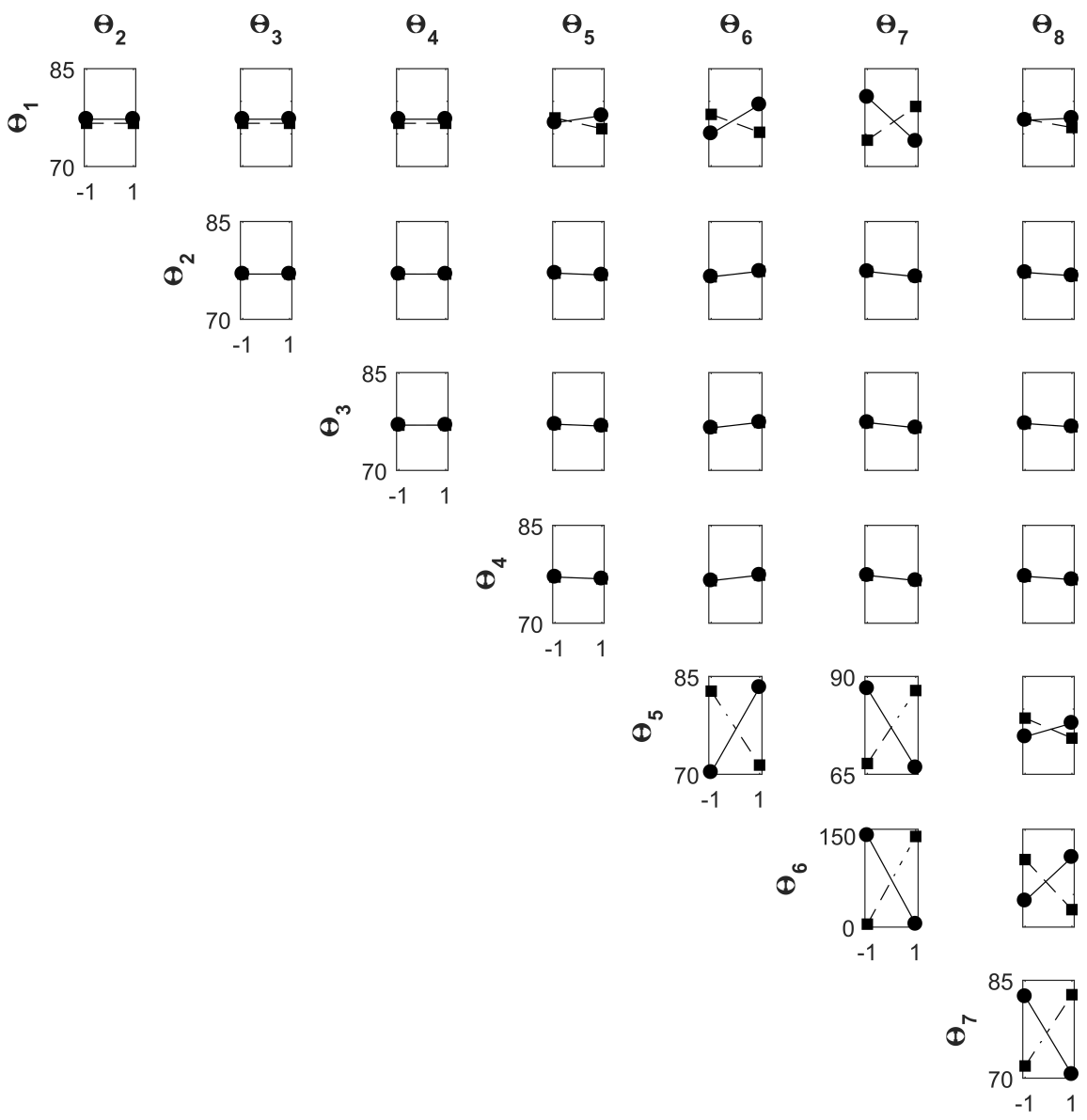

Figure 5.4: Two-parameter interaction plots between parameters $\Theta_{1}$ to $\Theta_{8}$. The response effect (sum of squared error) ranges from 70 to 85 unless otherwise indicated.

The most significant interactions occurred when there was uncertainty in the ethanol concentration of the equilibration and elution buffer and the column length. Column length might be considered as not changing over time, but a reduction of column length was observed in this study after 
cleaning-in-place of the column. These findings are in agreement with the results of Borg et al. [104] where the model was most sensitive to uncertainty in the ethanol concentration of the elution buffer of the investigated parameters total protein concentration, ethanol concentration and feed material purity.

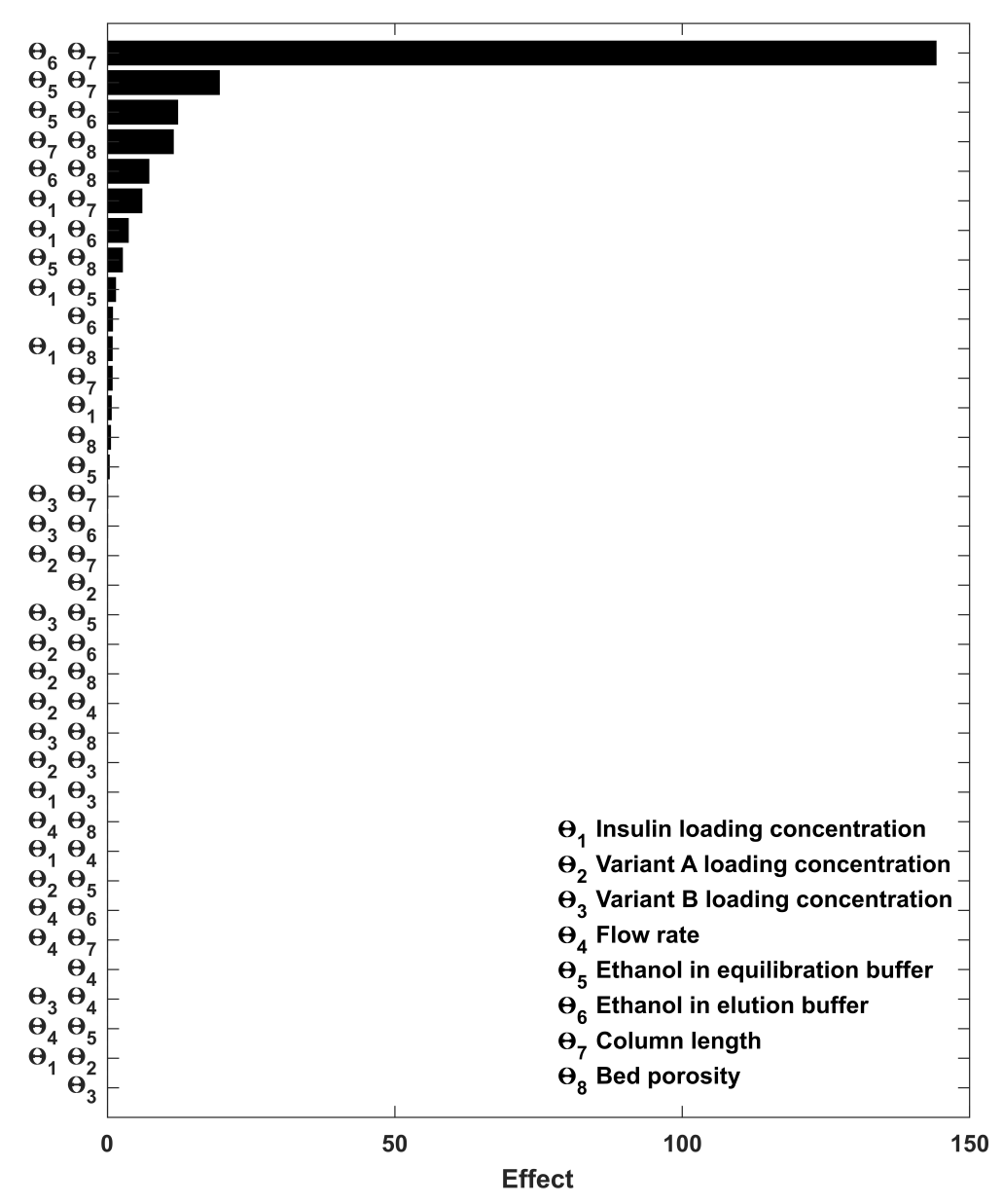

Figure 5.5: Ranking of model response effects of main effects and two-parameter interactions of the parameters $\Theta_{1}$ to $\Theta_{8}$.

The sensitivity analysis of the model demonstrated that specific parameters' uncertainty has a more significant impact on the model than others. But one should keep in mind that only minor variations of the parameters, in the margin of $\pm 1 \%$, were investigated. Bigger variations 
may occur e.g. in the loading concentrations due to the nature of biological systems. Therefore, the loading concentrations of the product and variant were quantified and provided to the mechanistic model for each run.

To implement mechanistic model-based monitoring for the reversed phase chromatography polishing step of insulin, the equilibration and elution buffer need to be prepared precisely. Furthermore, the column length should be reevaluated after CIP.

Mechanistic models of the various chromatography systems, such as ion exchange, hydrophobic interaction, and affinity, have been extensively published for process development [105-114]. Also, reversed phase chromatography and the separation of insulin on RPC have been modeled to evaluate column material, buffers and temperature effects [115-117]. Usually, mechanistic models are calibrated to the UV absorbance which needs to display a well-pronounced shoulder to model the impurity $[82,118]$. The mechanistic model utilized here, models low concentrated variants by calibrating the mechanistic model to quality control analytics, instead of to the unspecific UV absorbance spectrum. The presented monitoring tool emphasizes using mechanistic models as monitoring tools and relying on quality control data to predict variants accurately. The availability of mechanistic models of various chromatographic systems should facilitate their implementation as monitoring tools. Reliable analytical data needs to be available for the product and more importantly its variants. For each new chromatographic system, protein product, and additional variant of interest, the model needs to be calibrated and validated.

\subsection{PARAFAC-based multi-wavelength fluorescence monitoring}

The PARAFAC-based multi-wavelength fluorescence spectroscopy monitoring tool capitalizes on slight differences in the fluorescence of product variants compared to the product. PARAFAC reveals those fluorescence emission shifts and by extending the model to a PARAFAC regression model, quantitative information can be obtained.

For model calibration, the fluorescence spectra of the calibration data are arranged in a multi-way data cube. Preprocessing is performed to remove Raman and Rayleigh scattering. The data is modeled by PARAFAC which decomposes the data into scores, loadings and residuals (Figure 5.6). 


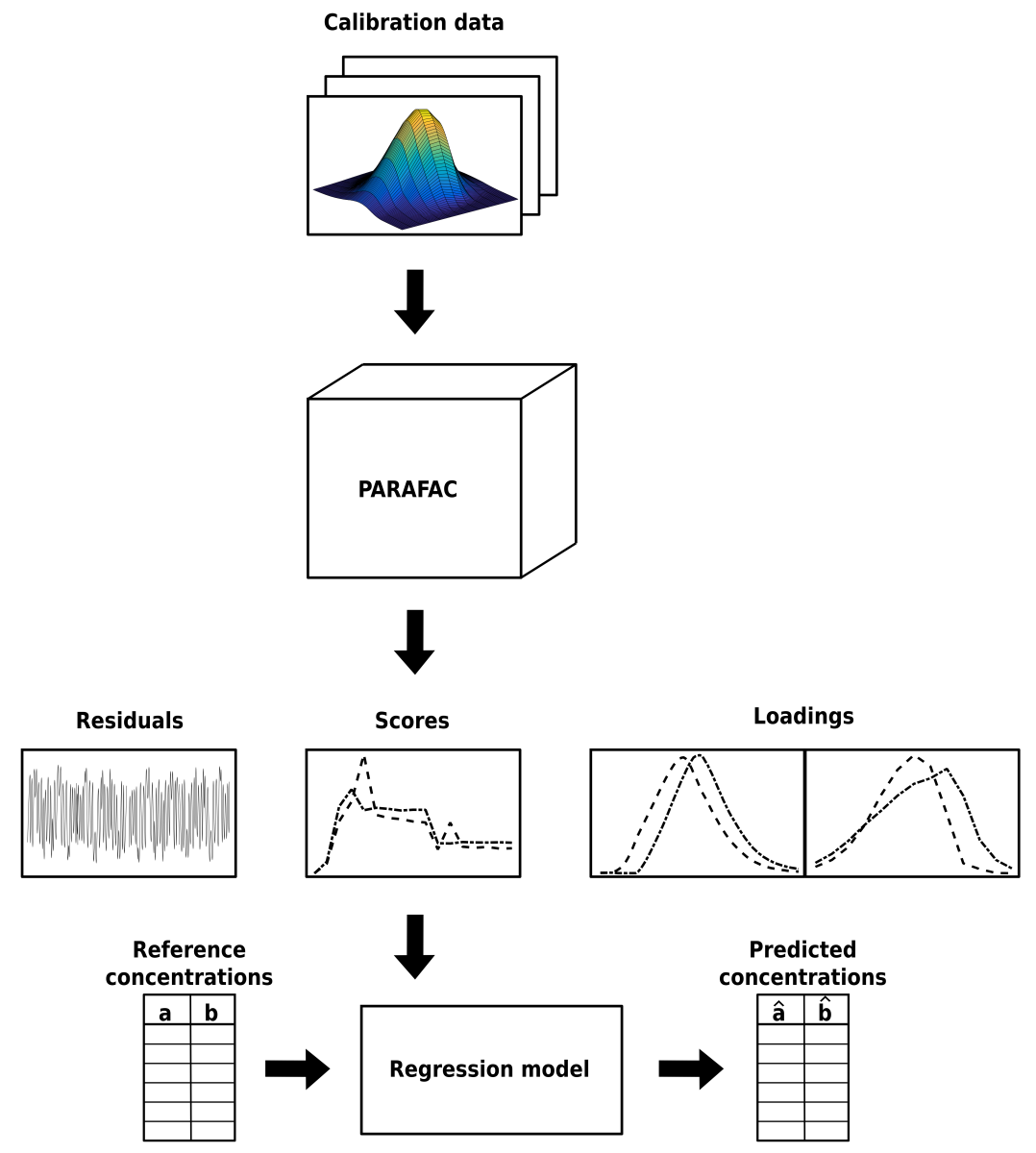

Figure 5.6: Concept of PARAFAC regression model. 
The PARAFAC model is established by comparing the emission and excitation mode loadings to single wavelength experiments of the analytes. The explained variance is considered as well as the core consistency and split-half analysis to establish the correct number of components. The scores of the PARAFAC model serve as the input of the regression model together with the reference concentration data to determine the regression coefficient. Once the regression coefficient has been determined, concentrations can be predicted.

For the validation of the model, independent data are generated which are preprocessed and modeled by the established PARAFAC model. The obtained scores are then further processed by the previously generated regression model to obtain the predicted concentrations of the validation data. By comparing the predicted concentrations to the actual ones, model error (RMSEC and RMSEP), as well as model fit and predictability can be evaluated.

This monitoring tool was first developed for an IgG protein test system where immunoglobulin A (IgA) represented an IgG dimer (Paper III). After successfully developing the monitoring tool for the test system, its adaption to monitor the chromatographic column outlets of three consecutive chromatography steps of an IgG purification allowed the evaluation of the monitoring tool for the real system (Figure 5.7).
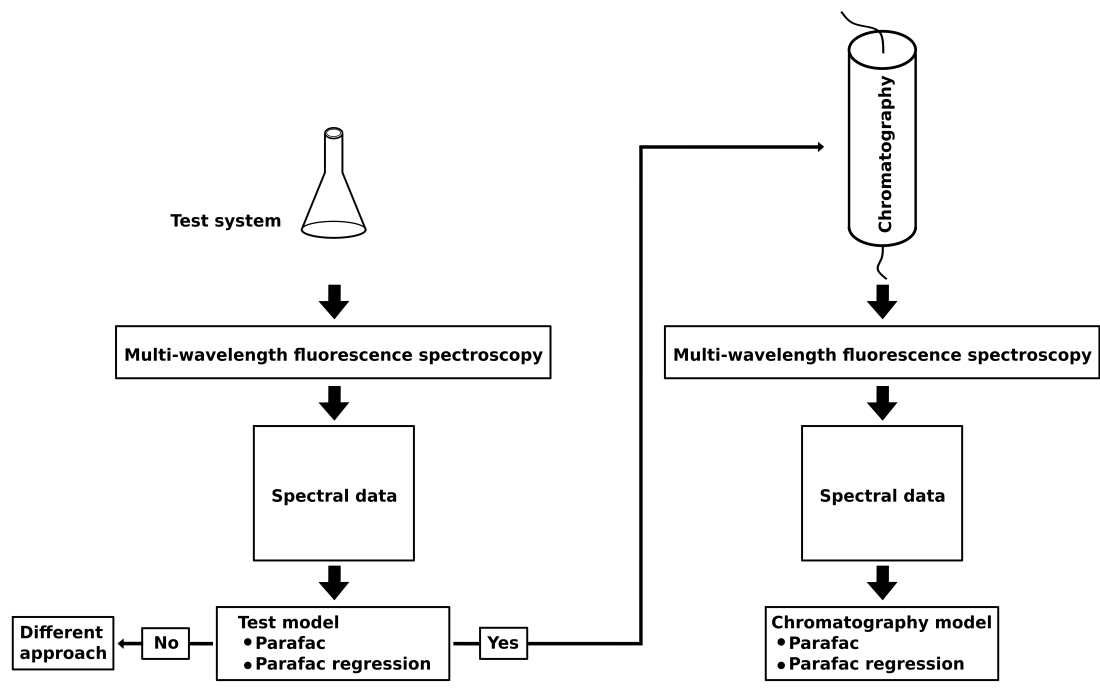

Figure 5.7: Development of PARAFAC-based fluorescence spectroscopy monitoring tool, first for a test system and then for chromatography system. 


\subsection{PARAFAC-BASED MULTI-WAVELENGTH FLUORESCENCE MONITORING}

The transferability of the monitoring tool was investigated by adapting the methodology from monitoring $\operatorname{IgG}$ and its aggregates to monitoring factor VIII, EPO, human growth hormone (Figure 5.8) and their respective variants (Paper IV). The methodology can be adapted to various proteins when the local environment of the tryptophan residues is affected upon variant formation. This change in the local tryptophan environment leading to fluorescence emission shifts is a requirement of the methodology. When the local environment of tryptophan is not affected in the product variant, as was the case for human growth hormone, the methodology could not be transferred.
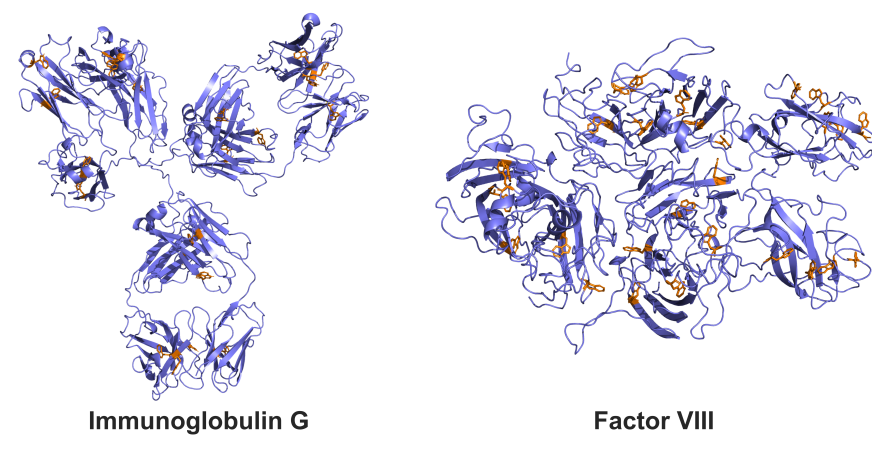

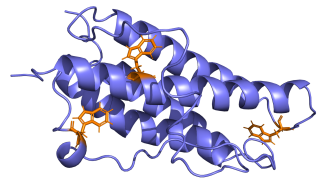

Erythropoietin

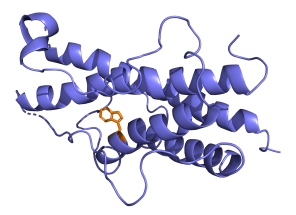

Human growth hormone

Figure 5.8: Protein structures with highlighted tryptophan residues of the investigated biopharmaceuticals. The structures were obtained from the RCSB data bank [119-122] and visualized with PyMOL Molecular Graphics System (Version 2.0, Schrödinger, LLC, NY, USA).

When adapting the monitoring tool from a test system to the real system, the lack of availability of pure variant has to be considered. The IgG test system included pure monomeric product and IgA as a representation for dimeric IgG. In the IgG affinity system, the factor VIII and EPO test system only pure monomer and samples containing both monomer and variant were available but not solely product variants. Comparing the IgG test system to the IgG affinity system as well as the factor VIII and EPO test system, PARAFAC was capable to identify the underlying 
components, independent of the presence of pure aggregate forms (Figure 5.9). But comparing the regression model of the monomer of each system, more scattering occurred in the IgG affinity system, the factor VIII and the EPO test system than in the IgG/ IgA test system. The goodness of fit $\mathrm{R}^{2}=0.99$ for the monomer in the $\operatorname{IgG} / \operatorname{IgA}$ test system and was 0.95 for the $\operatorname{IgG}$ affinity chromatography, the factor VIII and EPO test system, respectively (Table 5.2). The RMSEC of the monomer in the IgG test system is significantly smaller compared to the affinity chromatography system which also can be due to the smaller concentration range covered by the $\operatorname{IgG}$ test system. The concentration range of the variant is similar for each system. Increased scattering is observed in the systems where no pure aggregates were included (IgG affinity, factor VIII and EPO test system) (Figure 5.9). For the variant, the $\mathrm{R}^{2}$ is $0.99,0.83,0.74$ and 0.23 for the IgG test, the IgG affinity, the factor VIII and EPO test system, respectively. The RMSEC of the variant is highest for the EPO test system and lowest for the IgG/IgA test system. Therefore, the best fit and lowest model error of a product variant were obtained when samples solely consisting of product variants were included for model calibration.

PARAFAC itself identified underlying components, even at low concentrations, from pure monomer and sample mixtures. But the regression model could benefit from including pure variant samples if those can be generated sufficiently.

While the PARAFAC-based monitoring tool was implemented into an actual IgG purification process, the approach was developed only for the test system of factor VIII and EPO. The next step (Figure 5.7) would be to implement the approach into the downstream process of factor VIII and EPO where a wide concentration range should be covered, and pure variants might be generated to improve the regression model. Subsequently, pooling decisions of PARAFAC-based fluorescence monitoring could be compared to current practice pooling decisions to show the full potential of this monitoring tool.

Fluorescence spectroscopy has been used extensively in USP, e.g. to monitor biomass [47]. Also, the PARAFAC algorithm has been implemented for USP monitoring [123-127]. While the potential of fluorescence spectroscopy has been recognized for DSP monitoring [48], examples are rare [64, 128, 129]. For chromatography, PARAFAC has been used for handling retention shifts [130] or overlapping peaks [131]. In this thesis, PARAFAC is used to analyze fluorescence spectra of product variants for downstream process monitoring. 


\subsection{PARAFAC-BASED MULTI-WAVELENGTH FLUORESCENCE MONITORING}
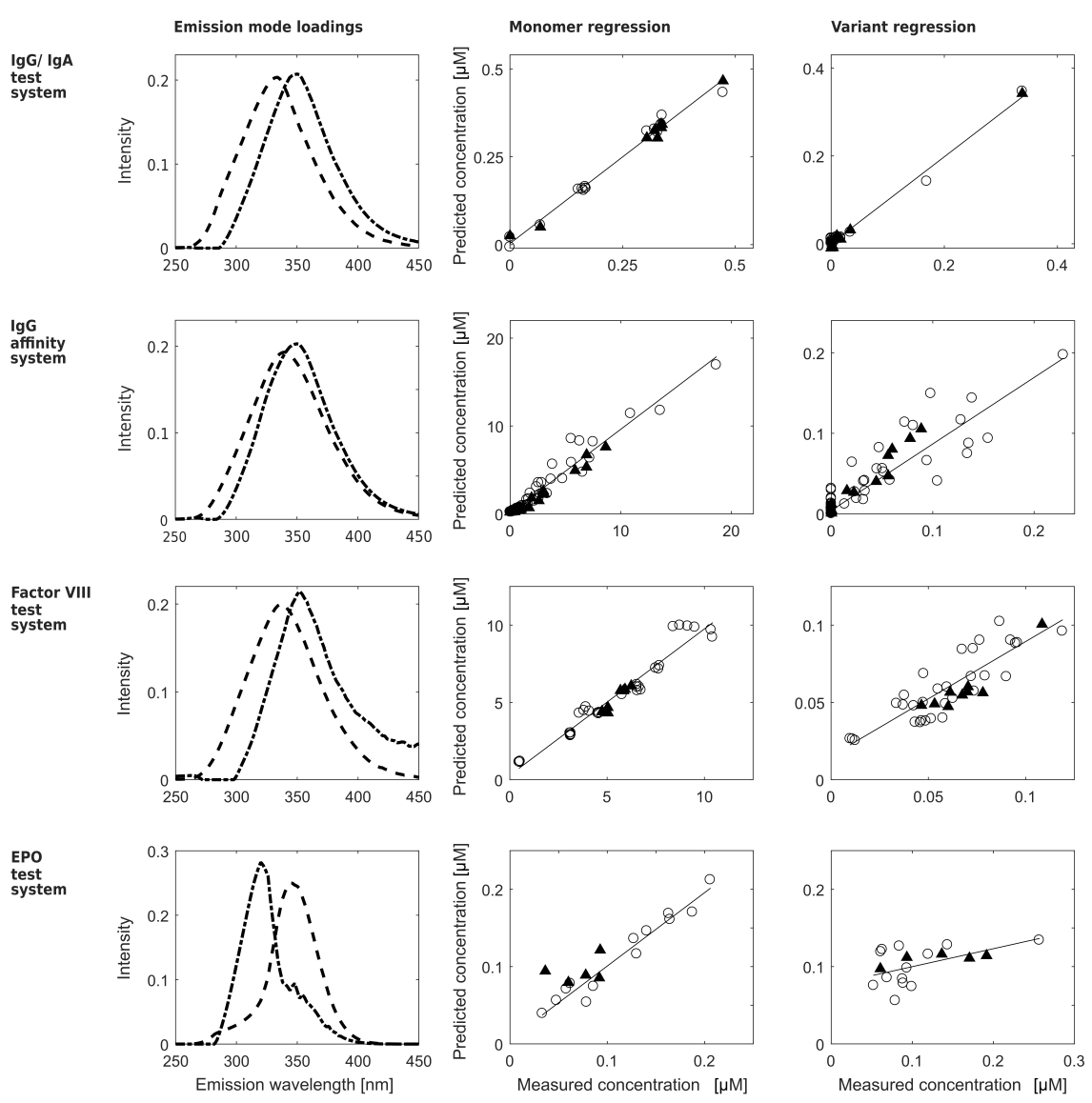

Figure 5.9: Comparison of PARAFAC emission mode loadings and regression models for monomer and variant of the $\operatorname{IgG} / \operatorname{IgA}$ test system, the IgG affinity chromatography system, the factor VIII and EPO test system. Component 1 (dashed line), component 2 (dashed-dotted line), calibration data (open circles), validation data (filled triangles).

Table 5.2: Comparison of $\mathrm{IgG} / \mathrm{IgA}$ test system, IgG affinity chromatography system, factor VIII and EPO test system regarding the goodness of fit $\left(\mathrm{R}^{2}\right)$ of the calibration data and the root mean square error (RMSEC) for monomer and variant.

\begin{tabular}{lllll} 
& \multicolumn{2}{c}{$\mathbf{R}^{2}$} & \multicolumn{2}{c}{ RMSEC [ $\boldsymbol{\mu M}]$} \\
& Monomer & Variant & Monomer & Variant \\
\hline & & & & \\
IgG/IgA test system & 0.99 & 0.99 & 0.016 & 0.009 \\
IgG affinity system & 0.95 & 0.83 & 0.685 & 0.020 \\
Factor VIII test system & 0.95 & 0.74 & 0.640 & 0.013 \\
EPO test system & 0.95 & 0.23 & 0.012 & 0.045 \\
& & & & \\
\hline
\end{tabular}




\subsection{A comparison of the developed monitoring tools}

The two monitoring tools established in this thesis were developed for product variants that are of importance as attributes of interest in bioprocesses. Each monitoring tool was developed for a different biopharmaceutical and their respective variants. The mechanistic model-based monitoring tool focused on insulin and two of its variants for monitoring of a reversed phase chromatography polishing step. The PARAFAC-based fluorescence spectroscopy monitoring tool was developed for the antibody IgG and its aggregates and subsequently, for factor VIII and EPO as well.

Even though both monitoring tools rely on different approaches, mechanistic and data-driven modeling, the monitoring tools can be compared regarding their performance (Table 5.3) as illustrated in Paper I. Both monitoring tools are of high biological relevance since both monitor product variants which are important and difficult to separate in biopharmaceutical downstream processing. The sensitivity of the mechanistic model-based monitoring tool is evaluated as higher than the PARAFAC-based fluorescence spectroscopy monitoring tool. Because the mechanistic model-based monitoring tool distinguishes between two different variants it also has a higher selectivity. Ways of improving the regression model of the PARAFAC-based monitoring tool have been discussed, but since not yet addressed, resulting in medium model accuracy. The accuracy of the mechanistic model-based monitoring tool is also evaluated as medium due to the model sensitivity toward uncertainty in the ethanol concentration of the buffers and column length.

To implement PARAFAC-based fluorescence spectroscopy monitoring, a multi-wavelength fluorescence spectrometer and an HPLC setup are required as well as software such as MATLAB (MathWorks, USA) with a toolbox containing PARAFAC. All of those are commercially available and user-friendly, making this monitoring tool ready for industrial practice. While there is modeling software available, those were not used to model the insulin reversed phase chromatography polishing step, making the development very time consuming and displaying lower user-friendliness. The computation time of the mechanistic model amounted to 15 seconds which makes it highly suitable to meet the soft sensor demands. The fluorescence spectral acquisition time of the PARAFAC-based monitoring tool was 5 minutes for only one sample. This analysis time would need to be significantly reduced to be feasible 
for a soft sensor setup, but the monitoring tool can be easily used for at-line monitoring. The amount of data required to calibrate the mechanistic model parameters was only a few experiments while the data-driven approach benefits from large datasets. Mechanistic model-based monitoring was used to establish pooling decisions that performed better than current practice but this was not evaluated for the PARAFAC-based monitoring tool. Similarly, the transferability of the methodology was only evaluated for PARAFAC-based fluorescence spectroscopy which indicates future work.

Table 5.3: A critical comparison of the developed monitoring tools regarding their characteristics, performance, and criteria, according to the author's experience.

\begin{tabular}{|c|c|c|}
\hline $\begin{array}{l}\text { Characteristics, performance, } \\
\text { criteria }\end{array}$ & $\begin{array}{l}\text { Mechanistic } \\
\text { model-based } \\
\text { monitoring tool }\end{array}$ & $\begin{array}{l}\text { PARAFAC-based } \\
\text { fluorescence } \\
\text { monitoring tool }\end{array}$ \\
\hline Product & Insulin & $\operatorname{IgG}$ \\
\hline Variants & 2 insulin variants & Aggregates \\
\hline Chromatography step & $\mathrm{RPC}$ & Affinity, AEX, CEX \\
\hline Biological relevance & +++ & +++ \\
\hline Sensitivity & +++ & ++ \\
\hline Selectivity & +++ & ++ \\
\hline Response time & +++ & ++ \\
\hline Accuracy & ++ & ++ \\
\hline Reproducibility & n.d. & n.d. \\
\hline Readiness for industrial practice & ++ & +++ \\
\hline Suitability as soft sensor & +++ & + \\
\hline Instrumentation required & HPLC & $\begin{array}{l}\text { HPLC, multi-wavelength } \\
\text { fluorescence spectrometer }\end{array}$ \\
\hline Model required & $\begin{array}{l}\text { Mechanistic model of } \\
\text { RPC }\end{array}$ & $\begin{array}{l}\text { PARAFAC, linear } \\
\text { regression }\end{array}$ \\
\hline Computation/measurement time & $15 \mathrm{~s}$ & $5 \mathrm{~min}$ \\
\hline Data amount & + & +++ \\
\hline Model user-friendliness & + & +++ \\
\hline $\begin{array}{l}\text { Time investment for } \\
\text { development }\end{array}$ & +++ & ++ \\
\hline $\begin{array}{l}\text { Pooling performance compared } \\
\text { to current practice }\end{array}$ & +++ & n.d. \\
\hline Transferability & n.d. & +++ \\
\hline
\end{tabular}

+ low; ++ medium; +++ high

n.d. - not determined 
In comparison, the mechanistic model-based monitoring tool showed a better performance than the PARAFAC-based fluorescence spectroscopy monitoring tool, but on the other hand, is also more time-consuming to develop than the latter.

For both monitoring tools, their advantages, drawbacks, as well as possible improvements were identified. Ultimately, the decision of what monitoring tool to choose will depend on the biopharmaceutical of interest and the intended use. 


\section{Chapter 6}

\section{Conclusion and outlook}

The main objective of this thesis is to enhance monitoring of biopharmaceutical downstream processing. The advantages of monitoring in downstream processing are discussed and critical attributes to monitor are highlighted. Further, analytical techniques that could be incorporated into monitoring tools are evaluated.

Product variants are identified as attributes of interest in this study. With these attributes in mind, monitoring tools and methodologies are developed based on existing monitoring and modeling approaches to be applicable for the biopharmaceutical industry.

For monitoring tools to be interesting to industry, valuable additional information should be provided, and real process improvements should be demonstrated. Methodologies applicable to various processes and different biopharmaceuticals might be desirable.

Different modeling approaches were utilized in this study, in particular, mechanistic and data-driven models. By modeling the process itself or data describing the process, understanding can be increased if the model accurately describes the relevant information of the process.

Two monitoring tools for chromatography were developed within this study to predict product variants of biopharmaceuticals. One utilized a mechanistic model describing reversed phase chromatography and by calibrating the model to quality control data instead of the unspecific UV absorbance, insulin and insulin variants were predicted. Product yield improvements were demonstrated when comparing the mechanistic model-based monitoring tool to current practice.

The second monitoring tool utilized the monitoring technique multi-wavelength fluorescence spectroscopy combined with parallel factor analysis regression. This monitoring tool was developed for 
monitoring aggregates in an antibody downstream process. The methodology was transferred to two additional biopharmaceuticals addressing the issue of developing more generic methodologies that demonstrate broader usefulness.

In future work, the mechanistic model-based monitoring tool could be extended to include additional variants, experimental errors causing model parameter uncertainty and model errors should be further studied to set up robust pooling decisions. The transferability to other chromatographic steps and biopharmaceuticals could be investigated. The data-driven approach would benefit from being adapted to industrial material of monoclonal antibodies, factor VIII and EPO. The regression model could be improved by including pure product variants and by covering a wide concentration range which would also allow assessing the linearity of the methodology. While the methodology provides additional information, the following step should be to evaluate process improvement by taking process decisions established by PARAFAC-based multi-wavelength fluorescence monitoring in comparison to current practice. To implement this methodology at a chromatography outlet, the analysis time needs to be reduced significantly and an on-line setup developed.

Those monitoring tools were developed at lab-scale, even though industrial material was used in one of the cases. When implementing monitoring tools into industrial settings, rigorous testing, qualification, extended validation, and verification are required.

Monitoring tools can support different phases of biopharmaceuticals' lifespan. In the process development phase at lab-scale and during scale-up, the additional information provided by the monitoring tools can be used to optimize the process and increase process understanding. At the later stage of manufacturing, the additional information can be used for troubleshooting. When monitoring tools are permanently installed, process control can be enabled.

Monitoring tools can be applied as part of process analytical technology to enable Quality by Design and thereby increase process understanding, take process decisions, enable process control as well as allowing for continuous improvements. While this thesis focused on the biopharmaceutical industry, the monitoring tools described could also be applicable in other areas involving protein or virus purification or e.g. chemical process industries. 
With the capability to distinguish between product and product variant, the developed monitoring tools, based on mechanistic and data-driven modeling approaches, are stepping stones to face the current challenges of the biopharmaceutical industry. 


\section{Acknowledgment}

I would like to thank my supervisor, Carl-Fredrik Mandenius, for your guidance and the opportunity to work on this exciting project, during which I learned a lot.

Thanks to my co-workers at the Division of Biotechnology, Jonas, Robert, and Judit, for your help, homemade biskvier and ice cream experiments and for always having an open ear and words of encouragement.

Thanks to the partners and members of BIORAPID for making this project possible, and for fun training weeks and courses. Especially, I would like to thank Matthias and Peter for the possibility to conduct experiments in their labs. I have appreciated working with you.

Thank you to Bernt, Anton, and Niklas for teaching me about mechanistic modeling. Thank you to Ivan for your patience and support while finding our project.

Thank you to the members of Forum Scientium and Charlotte, Stefan and Annette for making the graduate school a great way of getting exposed to other research and exchanging ideas.

Thank you to all current and former members of kaffeklubben and everybody who joins the lunch rounds for weird discussions and all the laughter. Thank you for making me feel welcome when I first came here. Thank you to all the people on whose door I knocked for helping me. Thanks for random meetings in corridors, discussions and fikas, for having a break, that sometimes even lead to aha-effects.

Ich möchte meiner Familie danken, für ihre unerschöpfliche Unterstützung auf dem Weg, der mich hierher geführt hat. Thank you to my friends afar for our long-lasting friendships.

A special thank you to Per for all your support, always being up for an adventure and your ability, no matter the situation, to put a smile on my face. 


\section{References}

[1] E. Moorkens, N. Meuwissen, I. Huys, P. Declerck, A. G. Vulto, and S. Simoens. The market of biopharmaceutical medicines: A snapshot of a diverse industrial landscape. Frontiers in Pharmacology, 8:314, 2017.

[2] D. Petrides, C. L. Cooney, L. B. Evans, R. P. Field, and M. Snoswell. Bioprocess simulation - an integrated approach to process development. Computers and Chemical Engineering, 13(45):553-561, 1989.

[3] D. Petrides, E. Sapidou, and J. Calandranis. Computer-aided process analysis and economic evaluation for biosynthetic human insulin production - A case study. Biotechnology and Bioengineering, 48(5):529-541, 1995.

[4] H.-J. Rehm, G. Reed, and K. Schügerl. Biotechnology Vol. 4. Measuring, modelling and control. VCH, Weinheim, 1990.

[5] G. Walsh. Biopharmaceutical benchmarks 2018. Nature Biotechnology, 36(12):1136-1145, 2018.

[6] E. Langer and R. A. Rader. Top trends in biopharmaceutical manufacturing, 2017. Pharmaceutical Technology, 41(9):58-60, 2017.

[7] R. A. Rader and E. Langer. Fifteen years of progress: Biopharmaceutical industry survey results. Pharmaceutical Technology, 42(7):5659, 2018.

[8] B. K. Nfor, P. D. E. M. Verhaert, L. A. M. van der Wielen, J. Hubbuch, and M. Ottens. Rational and systematic protein purification process development: the next generation. Trends in Biotechnology, 27(12):673-679, 2009. 
[9] W. S. Schlindwein and M. Gibson. Pharmaceutical Quality by Design: A practical approach. John Wiley and Sons Ltd, Hoboken, NJ, 2018.

[10] W. Soetaert and E. J. Vandamme. Industrial Biotechnology. WileyVCH Verlag, Weinheim, 2010.

[11] M. C. Flickinger. Upstream industrial biotechnology. John Wiley and Sons, Inc., Hoboken, NJ, 2013.

[12] A. L. Demain and P. Vaishnav. Production of recombinant proteins by microbes and higher organisms. Biotechnology Advances, 27(3):297-306, 2009.

[13] S. K. Niazi and J. L. Brown. Fundamentals of modern bioprocessing. CRC Press, Boca Raton, FL, 2017.

[14] M. C. Flickinger. Downstream industrial biotechnology: Recovery and purification. John Wiley and Sons, Inc., Hoboken, NJ, 2013.

[15] L. Hagel, G. Jagschies, and G. Sofer. Handbook of process chromatography: Development, manufacturing, validation and economics. Elsevier, London, 2008.

[16] F. Jameel, S. Hershenson, M. A. Khan, and S. Martin-Moe. Quality by Design for biopharmaceutical drug product development. Springer, New York, NY, 2016.

[17] C. K. Pan, F. Liu, and M. Motto. Identification of pharmaceutical impurities in formulated dosage forms. Journal of Pharmaceutical Sciences, 100(4):1228-1259, 2011.

[18] M. Vazquez-Rey and D. A. Lang. Aggregates in monoclonal antibody manufacturing processes. Biotechnology and Bioengineering, 108(7):1494-1508, 2011.

[19] M. Schiestl, T. Stangler, C. Torella, T. Cepeljnik, H. Toll, and R. Grau. Acceptable changes in quality attributes of glycosylated biopharmaceuticals. Nature Biotechnology, 29(4):310-312, 2011.

[20] U.S. Food and Drug Administration. Guidance for industry PAT - A framework for innovative pharmaceutical development, manufacturing, and quality assurance, 2004.

[21] ICH. ICH Harmonised Tripartite Guideline: Pharmaceutical development Q8 (R2), 2009. 
[22] ICH. ICH Harmonised Tripartite Guideline: Quality risk management Q9, 2005.

[23] ICH. ICH Harmonised Tripartite Guideline: Pharmaceutical quality system Q10, 2008.

[24] ICH. ICH Harmonised Tripartite Guideline: Development and manufacture of drug substances (Chemical entities and biotechnological/biological entities) Q11, 2012.

[25] R. Mhatre and A. S. Rathore. Quality by Design for biopharmaceuticals: Principles and case studies. John Wiley and Sons, Inc, Hoboken, NJ, 2009.

[26] J. Glassey, K. V. Gernaey, C. Clemens, T. W. Schulz, R. Oliveira, G. Striedner, and C. F. Mandenius. Process analytical technology (PAT) for biopharmaceuticals. Biotechnology fournal, 6(4):369-377, 2011.

[27] G. Dunnebier, S. Engell, A. Epping, F. Hanisch, A. Jupke, K. U. Klatt, and H. Schmidt-Traub. Model-based control of batch chromatography. AIChE fournal, 47(11):2493-2502, 2001.

[28] R. Mendhe, M. Thukkaram, N. Patil, and A. S. Rathore. Comparison of PAT based approaches for making real-time pooling decisions for process chromatography - use of feed forward control. Journal of Chemical Technology and Biotechnology, 90(2):341-348, 2015.

[29] I. M. Roitt, J. Brostoff, and D. K. Male. Immunology. Gower Medical Publishing Ltd., London, 1985.

[30] M. Z. Siddiqui. Monoclonal antibodies as diagnostics; an appraisal. Indian fournal of Pharmaceutical Sciences, 72(1):12-17, 2010.

[31] A. M. Scott, J. D. Wolchok, and L. J. Old. Antibody therapy of cancer. Nature Reviews Cancer, 12(4):278-287, 2012.

[32] A. A. Shukla, B. Hubbard, T. Tressel, S. Guhan, and D. Low. Downstream processing of monoclonal antibodies - Application of platform approaches. Journal of Chromatography B, 848(1):28-39, 2007.

[33] Uwe Gottschalk. Process scale purification of antibodies. John Wiley and Sons, Inc., Hoboken, NJ, second edition, 2017. 
[34] S. J. Shire. Monoclonal antibodies: meeting the challenges in manufacturing, formulation, delivery and stability of final drug product. Woodhead Publishing, Cambridge, 2015.

[35] H. C. Barfoed. Insulin production technology. Chemical Engineering Progress, 83(10):49-54, 1987.

[36] M. J. The. Human insulin: DNA technology's first drug. American Journal of Hospital Pharmacy, 46(11):S9-S11, 1989.

[37] R. G. Harrison, P. Todd, S. R. Rudge, and D. P. Petrides. Bioseparations science and engineering. Oxford University Press, Oxford, 2003.

[38] D. Baunsgaard, A. D. Nielsen, P. F. Nielsen, A. Henriksen, A. K. Kristensen, H. W. Bagger, and M. Ezban. A comparative analysis of heterogeneity in commercially available recombinant factor VIII products. Haemophilia, 24(6):880-887, 2018.

[39] J. M. Davis, T. Arakawa, T. W. Strickland, and D. A. Yphantis. Characterization of recombinant human erythropoietin produced in Chinese hamster ovary cells. Biochemistry, 26(9):2633-2638, 1987.

[40] W. Jelkmann. Erythropoietin - structure, control of production, and function. Physiological Reviews, 72(2):449-489, 1992.

[41] J. Powell and C. Gurk-Turner. Darbepoetin alfa (aranesp). Proceedings (Baylor University. Medical Center), 15(3):332-335, 2002.

[42] M. L. Vance and N. Mauras. Growth hormone therapy in adults and children. New England fournal of Medicine, 341(16):1206-1216, 1999.

[43] E. B. Jensen and S. Carlsen. Production of recombinant human growth-hormone in Escherichia coli - expression of different precursors and physiological effects of glucose, acetate, and salts. Biotechnology and Bioengineering, 36(1):1-11, 1990.

[44] M. J. T. Carrondo, P. M. Alves, N. Carinhas, J. Glassey, F. Hesse, O.-W. Merten, M. Micheletti, T. Noll, R. Oliveira, U. Reichl, A. Staby, A. P. Teixeira, H. Weichert, and C.-F. Mandenius. How can measurement, monitoring, modeling and control advance cell culture in industrial biotechnology? Biotechnology fournal, 7(12):1522-1529, 2012. 
[45] P. Roch and C.-F. Mandenius. On-line monitoring of downstream bioprocesses. Current Opinion in Chemical Engineering, 14:112-120, 2016.

[46] W. Göpel, J. Hesse, and J. N. Zemel. Sensors a comprehensive survey Volume 3. VCH, Weinheim, 1992.

[47] J. Classen, F. Aupert, K. F. Reardon, D. Solle, and T. Scheper. Spectroscopic sensors for in-line bioprocess monitoring in research and pharmaceutical industrial application. Analytical and Bioanalytical Chemistry, 409(3):651-666, 2017.

[48] A. S. Rathore and G. Kapoor. Application of process analytical technology for downstream purification of biotherapeutics. fournal of Chemical Technology and Biotechnology, 90(2):228-236, 2015.

[49] M. Rüdt, T. Briskot, and J. Hubbuch. Advances in downstream processing of biologics - Spectroscopy: An emerging process analytical technology. Journal of Chromatography A, 1490:2-9, 2017.

[50] Karl Schügerl. Bioreaction engineering, volume 3. John Wiley and Sons Ltd., Chichester, 1997.

[51] V. Vojinovic, J. M. S. Cabral, and L. P. Fonseca. Real-time bioprocess monitoring part I: In situ sensors. Sensors and Actuators B, 114(2):1083-1091, 2006.

[52] E. K. Read, J. T. Park, R. B. Shah, B. S. Riley, K. A. Brorson, and A. S. Rathore. Process analytical technology (PAT) for biopharmaceutical products: Part I. concepts and applications. Biotechnology and Bioengineering, 105(2):276-284, 2010.

[53] K. A. Bakeev. Process analytical technology: Spectroscopic tools and implementation strategies for the chemical and pharmaceutical industries. Blackwell Publishing Ltd, Oxford, 2005.

[54] Z. P. Chen, D. Lovett, and J. Morris. Process analytical technologies and real time process control a review of some spectroscopic issues and challenges. Fournal of Process Control, 21(10):1467-1482, 2011.

[55] G. Gauglitz and T. Vo-Dinh. Handbook of spectroscopy. Wiley-VCH, Weinheim, 2003.

[56] G. G. Hammes. Spectroscopy for the biological sciences. John Wiley and Sons, Inc., Hoboken, NJ, 2005. 
[57] N. Brestrich, A. Sanden, A. Kraft, K. McCann, J. Bertolini, and J. Hubbuch. Advances in inline quantification of co-eluting proteins in chromatography: Process-data-based model calibration and application towards real-life separation issues. Biotechnology and Bioengineering, 112(7):1406-1416, 2015.

[58] N. Brestrich, M. Rüdt, D. Buchler, and J. Hubbuch. Selective protein quantification for preparative chromatography using variable pathlength UV/Vis spectroscopy and partial least squares regression. Chemical Engineering Science, 176:157-164, 2018.

[59] M. Rüdt, N. Brestrich, L. Rolinger, and J. Hubbuch. Real-time monitoring and control of the load phase of a Protein A capture step. Biotechnology and Bioengineering, 114(2):368-373, 2017.

[60] F. Capito, R. Skudas, H. Kolmar, and B. Stanislawski. Host cell protein quantification by fourier transform mid infrared spectroscopy (FT-MIR). Biotechnology and Bioengineering, 110(1):252-259, 2013.

[61] F. Capito, R. Skudas, H. Kolmar, and C. Hunzinger. At-line mid infrared spectroscopy for monitoring downstream processing unit operations. Process Biochemistry, 50(6):997-1005, 2015.

[62] S. Grosshans, M. Rüdt, A. Sanden, N. Brestrich, J. Morgenstern, S. Heissler, and J. Hubbuch. In-line Fourier-transform infrared spectroscopy as a versatile process analytical technology for preparative protein chromatography. Journal of Chromatography A, 1547:37-44, 2018.

[63] M. Boulet-Audet, S. G. Kazarian, and B. Byrne. In-column ATRFTIR spectroscopy to monitor affinity chromatography purification of monoclonal antibodies. Scientific Reports, 6:30526, 2016.

[64] A. S. Rathore, X. Li, W. Bartkowski, A. Sharma, and Y. Lu. Case study and application of process analytical technology (PAT) towards bioprocessing: Use of tryptophan fluorescence as at-line tool for making pooling decisions for process chromatography. Biotechnology Progress, 25(5):1433-1439, 2009.

[65] Z. Yu, J. C. Reid, and Y. P. Yang. Utilizing dynamic light scattering as a process analytical technology for protein folding and aggregation monitoring in vaccine manufacturing. Fournal of Pharmaceutical Sciences, 102(12):4284-4290, 2013. 
[66] B. A. Patel, A. Gospodarek, M. Larkin, S. A. Kenrick, M. A. Haverick, N. Tugcu, M. A. Brower, and D. D. Richardson. Multi-angle light scattering as a process analytical technology measuring real-time molecular weight for downstream process control. Mabs, 10(7):945950, 2018.

[67] M. R. Eftink. Fluorescence Techniques for Studying Protein Structure, pages 127-205. John Wiley and Sons, Inc., New York, NY, 1991.

[68] W. Jiskoot and D. J. A. Crommelin. Methods for structural analysis of protein pharmaceuticals. AAPS Press, Arlington, VA, 2005.

[69] J. R. Lakowicz. Principles of fluorescence spectroscopy. Springer, New York, NY, third edition, 2006.

[70] C. A. Royer. Probing protein folding and conformational transitions with fluorescence. Chemical Reviews, 106(5):1769-1784, 2006.

[71] R. Luttmann, D. G. Bracewell, G. Cornelissen, K. V. Gernaey, J. Glassey, V. C. Hass, C. Kaiser, C. Preusse, G. Striedner, and C.F. Mandenius. Soft sensors in bioprocessing: A status report and recommendations. Biotechnology fournal, 7(8):1040-1048, 2012.

[72] C.-F. Mandenius and Gustavsson R. Mini-review: Soft sensors as means for PAT in the manufacture of bio-therapeutics. Fournal of Chemical Technology and Biotechnology, 90(2):215-227, 2015.

[73] P. Kadlec, B. Gabrys, and S. Strandt. Data-driven soft sensors in the process industry. Computers and Chemical Engineering, 33(4):795814, 2009.

[74] A. Golabgir, T. Hoch, M. Zhariy, and C. Herwig. Observability analysis of biochemical process models as a valuable tool for the development of mechanistic soft sensors. Biotechnology Progress, 31(6):1703-1715, 2015.

[75] M. von Stosch, S. Davy, K. Francois, V. Galvanauskas, J. M. Hamelink, A. Luebbert, M. Mayer, R. Oliveira, R. O'Kennedy, P. Rice, and J. Glassey. Hybrid modeling for Quality by Design and PAT - benefits and challenges of applications in biopharmaceutical industry. Biotechnology fournal, 9(6):719-726, 2014.

[76] A. Cheruy. Software sensors in bioprocess engineering. Fournal of Biotechnology, 52(3):193-199, 1997. 
[77] C.-F. Mandenius and N. J. Titchener-Hooker. Measurement, monitoring, modelling and control of bioprocesses. Springer Verlag, Heidelberg, 2013.

[78] H. Schmidt-Traub. Preparative chromatography of fine chemicals and pharmaceutical agents. Wiley-VCH, Weinheim, 2005.

[79] G. Guiochon. Preparative liquid chromatography. fournal of Chromatography A, 965(1-2):129-161, 2002.

[80] G. Guiochon, A. Felinger, D.G. Shirazi, and A.M. Katti. Fundamentals of preparative and nonlinear chromatography. Elsevier, San Diego, CA, 2006.

[81] J. M. Mollerup. A review of the thermodynamics of protein association to ligands, protein adsorption, and adsorption isotherms. Chemical Engineering and Technology, 31(6):864-874, 2008.

[82] M. Degerman, N. Jakobsson, and B. Nilsson. Modeling and optimization of preparative reversed-phase liquid chromatography for insulin purification. Journal of Chromatography A, 1162(1):4149, 2007.

[83] P. Roch, A. Sellberg, N. Andersson, M. Gunne, P. Hauptmann, B. Nilsson, and C. F. Mandenius. Model-based monitoring of industrial reversed phase chromatography to predict insulin variants. Biotechnology Progress, 35(4):e2813, 2019.

[84] R. P. W. Scott and C. Reese. Precision of contemporary liquid chromatographic measurements. Journal of Chromatography, 138(2):283-307, 1977.

[85] D. B. Hibbert, J. X. Jiang, and M. I. Mulholland. Propagation of uncertainty in high-performance liquid chromatography with UVVIS detection. Analytica Chimica Acta, 443(2):205-214, 2001.

[86] N. Borg, K. Westerberg, S. Schnittert, E. von Lieres, and B. Nilsson. Numerical analysis of model parameter uncertainties as a result of experimental uncertainty - An example from preparative chromatography. IFAC Proceedings Volumes, 45(2):991-995, 2012.

[87] M. Ionescu-Bujor and D. G. Cacuci. A comparative review of sensitivity and uncertainty analysis of large-scale systems-I: 
Deterministic methods. Nuclear Science and Engineering, 147(3):189-203, 2004.

[88] D. G. Cacuci and M. Ionescu-Bujor. A comparative review of sensitivity and uncertainty analysis of large-scale systems - II: Statistical methods. Nuclear Science and Engineering, 147(3):204217, 2004.

[89] B. D. Kelley, P. Jennings, R. Wright, and C. Briasco. Demonstrating process robustness for chromatographic purification of a recombinant protein. Biopharm, 10(10):36-47, 1997.

[90] J. Antony. Design of experiments for engineers and scientists. Elsevier, Oxford, 2003.

[91] W. W. Cooley and P. R. Lohnes. Multivariate data analysis. John Wiley and Sons, Inc., New York, NY, 1971.

[92] P. Gemperline. Practical guide to chemometrics. CRC Press, Boca Raton, FL, second edition, 2006.

[93] L. Eriksson, T. Bryne, E. Johansson, J. Trygg, and C. Vikström. Multiand megavariate data analysis: Basic principles and applications. MKS Umetrics AB, Malmö, third edition, 2013.

[94] R. Bro and A. K. Smilde. Principal component analysis. Analytical Methods, 6(9):2812-2831, 2014.

[95] M. Höhse, J. Alves-Rausch, A. Prediger, P. Roch, and C. Grimm. Near-infrared spectroscopy in upstream bioprocesses. Pharmaceutical Bioprocessing, 3(2):153-172, 2015.

[96] H. Martens and T. Næs. Multivariate calibration. John Wiley and Sons Ltd, Chichester, 1991.

[97] R. Bro. PARAFAC. Tutorial and applications. Chemometrics and Intelligent Laboratory Systems, 38(2):149-171, 1997.

[98] Y. Hayashi and R. Matsuda. Uncertainty Structure, Information Theory, and Optimization of Quantitative Analysis in Separation Science, volume 34, pages 347-423. Marcel Dekker, New York, NY, 1994. 
[99] D. Solle, B. Hitzmann, C. Herwig, M. P. Remelhe, S. Ulonska, L. Wuerth, A. Prata, and T. Steckenreiter. Between the poles of datadriven and mechanistic modeling for process operation. Chemie Ingenieur Technik, 89(5):542-561, 2017.

[100] A. Osberghaus, S. Hepbildikler, S. Nath, M. Haindl, E. von Lieres, and J. Hubbuch. Optimizing a chromatographic three component separation: A comparison of mechanistic and empiric modeling approaches. Journal of Chromatography A, 1237:86-95, 2012.

[101] P. Baumann and J. Hubbuch. Downstream process development strategies for effective bioprocesses: Trends, progress, and combinatorial approaches. Engineering in Life Sciences, 17(11):11421158, 2017.

[102] K. Westerberg, N. Borg, N. Andersson, and B. Nilsson. Supporting design and control of a reversed-phase chromatography step by mechanistic modeling. Chemical Engineering and Technology, 35(1):169-175, 2012.

[103] K. Arkell, H. K. Knutson, S. S. Frederiksen, M. P. Breil, and B. Nilsson. Pareto-optimal reversed-phase chromatography separation of three insulin variants with a solubility constraint. Journal of Chromatography A, 1532:98-104, 2018.

[104] N. Borg, K. Westerberg, N. Andersson, E. von Lieres, and B. Nilsson. Effects of uncertainties in experimental conditions on the estimation of adsorption model parameters in preparative chromatography. Computers and Chemical Engineering, 55:148-157, 2013.

[105] J. M. Mollerup, T. B. Hansen, S. Kidal, L. Sejergaard, and A. Staby. Development, modelling, optimisation and scale-up of chromatographic purification of a therapeutic protein. Fluid Phase Equilibria, 261(1-2):133-139, 2007.

[106] E. J. Close, J. R. Salm, D. G. Bracewell, and E. Sorensen. Modelling of industrial biopharmaceutical multicomponent chromatography. Chemical Engineering Research and Design, 92(7):1304-1314, 2014.

[107] B. Guelat, G. Strohlein, M. Lattuada, L. Delegrange, P. Valax, and M. Morbidelli. Simulation model for overloaded monoclonal antibody variants separations in ion-exchange chromatography. fournal of Chromatography A, 1253:32-43, 2012. 
[108] R. Khalaf, J. Heymann, X. LeSaout, F. Monard, M. Costioli, and M. Morbidelli. Model-based high-throughput design of ion exchange protein chromatography. Journal of Chromatography $A$, 1459:67-77, 2016.

[109] O. Khanal, V. Kumar, K. Westerberg, F. Schlegel, and A. M. Lenhoff. Multi-column displacement chromatography for separation of charge variants of monoclonal antibodies. fournal of Chromatography A, 1586:40-51, 2019.

[110] D. Nagrath, F. Xia, and S. M. Cramer. Characterization and modeling of nonlinear hydrophobic interaction chromatographic systems. Journal of Chromatography A, 1218(9):1219-1226, 2011.

[111] E. X. Perez-Almodovar and G. Carta. IgG adsorption on a new protein a adsorbent based on macroporous hydrophilic polymers II. Pressure-flow curves and optimization for capture. fournal of Chromatography A, 1216(47):8348-8354, 2009.

[112] G. Sandoval, C. Shene, B. A. Andrews, and J. A. Asenjo. Extension of the selection of protein chromatography and the rate model to affinity chromatography. Journal of Molecular Recognition, 23(6):609-617, 2010.

[113] L. K. Shekhawat, M. Chandak, and A. S. Rathore. Mechanistic modeling of hydrophobic interaction chromatography for monoclonal antibody purification: Process optimization in the Quality by Design paradigm. Journal of Chemical Technology and Biotechnology, 92(10):2527-2537, 2017.

[114] F. Steinebach, M. Angarita, D. J. Karst, T. Müller-Späth, and M. Morbidelli. Model based adaptive control of a continuous capture process for monoclonal antibodies production. Fournal of Chromatography A, 1444:50-56, 2016.

[115] D. Getaz, N. Dogan, N. Forrer, and M. Morbidellia. Influence of the pore size of reversed phase materials on peptide purification processes. Fournal of Chromatography A, 1218(20):2912-2922, 2011.

[116] K. Arkell, M. P. Breil, S. S. Frederiksen, and B. Nilsson. Mechanistic modeling of reversed-phase chromatography of insulins with potassium chloride and ethanol as mobile-phase modulators. ACS Omega, 2(1):136-146, 2017. 
[117] K. Arkell, M. P. Breil, S. S. Frederiksen, and B. Nilsson. Mechanistic modeling of reversed-phase chromatography of insulins within the temperature range 10-40 degrees C. ACS Omega, 3(2):1946-1954, 2018.

[118] K. Johansson, S. S. Frederiksen, M. Degerman, M. P. Breil, J. M. Mollerup, and B. Nilsson. Combined effects of potassium chloride and ethanol as mobile phase modulators on hydrophobic interaction and reversed-phase chromatography of three insulin variants. Journal of Chromatography A, 1381:64-73, 2015.

[119] PDB ID: 1HGU, L. Chantalat, N.D. Jones, F. Korber, J. Navaza, and A.G. Pavlovsky. The crystal-structure of wild-type growth-hormone at 2.5 Angstrom resolution. Protein and Peptide Letters, 2(2):333-340, 1995.

[120] PDB ID: 1BUY, J. C. Cheetham, D. M. Smith, K. H. Aoki, J. L. Stevenson, T. J. Hoeffel, R. S. Syed, J. Egrie, and T. S. Harvey. NMR structure of human erythropoietin and a comparison with its receptor bound conformation. Nature Structural and Molecular Biology, 5(10):861-6, 1998.

[121] PDB ID: 1IGY, L. J. Harris, E. Skaletsky, and A. McPherson. Crystallographic structure of an intact IgG1 monoclonal antibody. Journal of Molecular Biology, 275(5):861-872, 1998.

[122] PDB ID: 3CDZ, J. C. Ngo, M. Huang, D. A. Roth, B. C. Furie, and B. Furie. Crystal structure of human factor VIII: implications for the formation of the factor IXa-factor VIIIa complex. Structure, 16(4):597-606, 2008.

[123] J. M. Amigo, A. Surribas, J. Coello, J. L. Montesinos, S. Maspoch, and F. Valero. On-line parallel factor analysis. A step forward in the monitoring of bioprocesses in real time. Chemometrics and Intelligent Laboratory Systems, 92(1):44-52, 2008.

[124] M. B. Haack, A. Eliasson, and L. Olsson. On-line cell mass monitoring of saccharomyces cerevisiae cultivations by multiwavelength fluorescence. Fournal of Biotechnology, 114(1-2):199208, 2004.

[125] M. B. Haack, A. E. Lantz, P. P. Mortensen, and L. Olsson. Chemometric analysis of in-line multi-wavelength fluorescence 
measurements obtained during cultivations with a lipase producing aspergillus oryzae strain. Biotechnology and Bioengineering, 96(5):904-913, 2007.

[126] P. Odman, C. L. Johansen, L. Olsson, K. V. Gernaey, and A. E. Lantz. On-line estimation of biomass, glucose and ethanol in saccharomyces cerevisiae cultivations using in-situ multi-wavelength fluorescence and software sensors. Fournal of Biotechnology, 144(2):102-112, 2009.

[127] A. Surribas, J. M. Amigo, J. Coello, J. L. Montesinos, F. Valero, and S. Maspoch. Parallel factor analysis combined with PLS regression applied to the on-line monitoring of Pichia pastoris cultures. Analytical and Bioanalytical Chemistry, 385(7):1281-1288, 2006.

[128] D. G. Sauer, M. Melcher, M. Mosor, N. Walch, M. Berkemeyer, T. Scharl-Hirsch, F. Leisch, A. Jungbauer, and A. Dürauer. Realtime monitoring and model-based prediction of purity and quantity during a chromatographic capture of fibroblast growth factor 2 . Biotechnology and Bioengineering, 116(8):1999-2009, 2019.

[129] N. Walch, T. Scharl, E. Felföldi, D. G. Sauer, M. Melcher, F. Leisch, A. Dürauer, and A. Jungbauer. Prediction of the quantity and purity of an antibody capture process in real time. Biotechnology fournal, 14(7):1800521, 2019.

[130] R. Bro, C. A. Andersson, and H. A. L. Kiers. PARAFAC2 - Part II. Modeling chromatographic data with retention time shifts. Fournal of Chemometrics, 13(3-4):295-309, 1999.

[131] J. M. Amigo, M. J. Popielarz, R. M. Callejon, M. L. Morales, A. M. Troncoso, M. A. Petersen, and T. B. Toldam-Andersen. Comprehensive analysis of chromatographic data by using PARAFAC2 and principal components analysis. fournal of Chromatography $A$, 1217(26):4422-4429, 2010. 


\section{Papers}

The papers associated with this thesis have been removed for copyright reasons. For more details about these see:

http://urn.kb.se/resolve?urn=urn:nbn:se:liu:diva-160524 


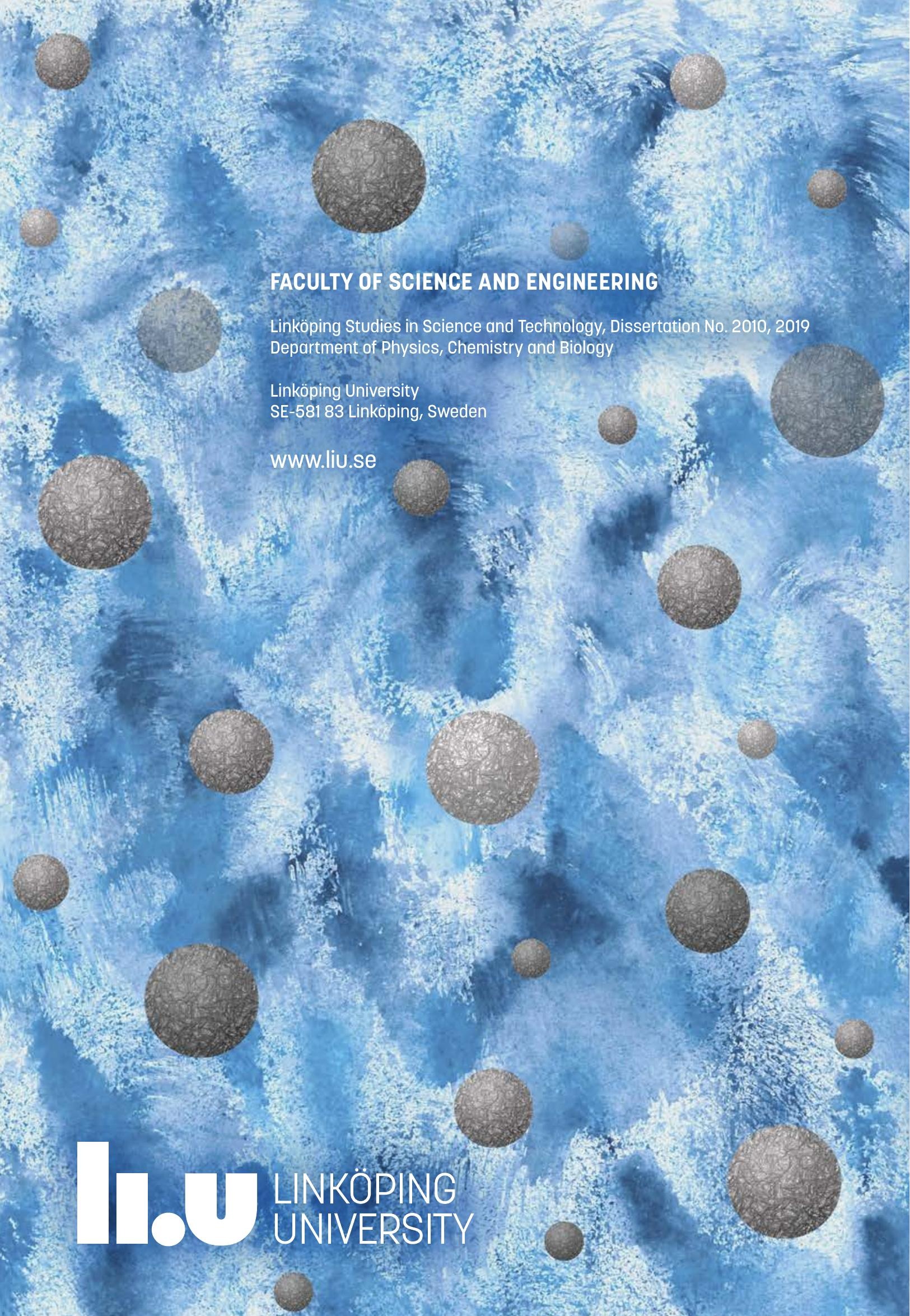

